\title{
APPROACHES IN DEMOGRAPHIC MODELING FOR PREDICTING POPULATION PERSISTENCE ACROSS A MOISTURE GRADIENT OF AN INVASIVE, HYBRIDIZING WEED (RAPHANUS SPP.)
}

\author{
by \\ Zachary Teitel \\ Honours BSc University of Toronto, 2011
}

A thesis presented to Ryerson University

\author{
in partial fulfillment of the \\ requirements for the degree of \\ Master of Science \\ in the Program of \\ Molecular Science
}

Toronto, Ontario, Canada, 2014

CZachary Teitel 2014 


\section{AUTHOR'S DECLARATION FOR ELECTRONIC SUBMISSION OF A THESIS}

I hereby declare that I am the sole author of this thesis. This is a true copy of the thesis, including any required final revisions, as accepted by my examiners.

I authorize Ryerson University to lend this thesis to other institutions or individuals for the purpose of scholarly research.

I further authorize Ryerson University to reproduce this thesis by photocopying or by other means, in total or in part, at the request of other institutions or individuals for the purpose of scholarly research.

I understand that my thesis may be made electronically available to the public. 


\section{$\underline{\text { ABSTRACT }}$ \\ APPROACHES IN DEMOGRAPHIC MODELING FOR PREDICTING POPULATION PERSISTENCE ACROSS A MOISTURE GRADIENT OF AN INVASIVE, HYBRIDIZING WEED (RAPHANUS SPP.)}

Zachary Teitel, Master of Science

Molecular Science, Ryerson University, 2014

Human-induced global climate change has altered precipitation patterns, with consequences for weed infestations. Cultivated plants are known to readily hybridize with their wild relatives, which may create more problematic weeds in future environments. I compared the demography and seed bank dynamics of wild radish and crop-wild hybrid radish populations across a soil moisture gradient. In a seed-burial experiment and weekly population censuses, I assessed frequency and timing of various demographic parameters. Germination rates declined with time in the low rain treatment, but increased in the double rain treatment. Wild seedlings tended to emerge later than hybrid seedlings. Hybrid populations had marginally higher population growth rates $(\lambda)$ than wild populations. Fecundity had the greatest influence on $\lambda$. This study better informs weed control measures by predicting seed banks' role in population persistence and by isolating the most effective life-history stage 'choke point' to suppress population growth given new climate change scenarios.

Keywords: LTRE, demography, vital rate, crop-wild hybridization, climate change, soil moisture, seedbank 


\section{ACKNOWLEDGMENTS}

I firstly want to thank my supervisor, Dr. Lesley Campbell, for her unwavering support of my work over the entire course of my degree. Through her exceptional academic guidance and relentless excitement, she has inspired me to be the best scientist I can be. Many invaluable colleagues have helped me put together the many components of this thesis, including current and former Campbell Lab members and volunteers, committee members, and staff. Finally, I am so grateful for all of the emotional and material support generously provided by my friends, family and Ilana. 


\section{CONTRIBUTIONS OF AUTHORS:}

\section{CHAPTER 2.}

Dr. Lesley Campbell and I were responsible for the initial conceptualization of the idea. Together we decided on treatments, replicates, and materials needed, with Dr. Campbell supplying funding for all fieldwork and personnel. I completed data collection with the help of research assistants, volunteers and data analysis with the guidance of Dr. Campbell and Dr. Andrew Laursen. I was also responsible for the write up of all drafts, with Dr. Campbell contributing edits.

\section{CHAPTER 3.}

Dr. Lesley Campbell and I were responsible for the initial conceptualization of the idea. Together we decided on treatments, replicates, and materials needed, with Dr. Campbell supplying funding for all fieldwork and personnel. I completed data collection with the help of research assistants (specifically Agnes Klimowski) and volunteers. I performed all the matrix model analyses and subsequent analyses including lambda as the response variable, under the guidance of Drs. Campbell and Laursen. Dr. Campbell \& Agnes Klimowski performed the data analysis using $r$ as the response variable. I was also responsible for the write up of all drafts, with Dr. Campbell contributing edits. 


\section{TABLE OF CONTENTS}

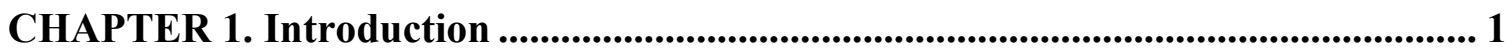

1.1 Crop-wild Hybridization and the Evolution of Increasingly Invasive Lineages ............. 1

1.2 Experimental Approaches ......................................................................................................4

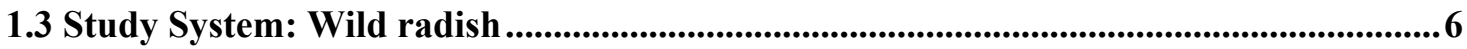

CHAPTER 2. Seed Dormancy and Germination of Wild and Crop-Wild Hybrid

Raphanus Across a Soil Moisture Gradient........................................................... 8

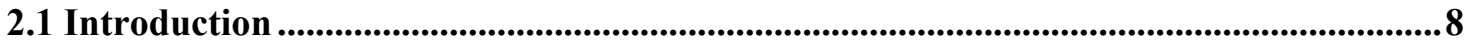

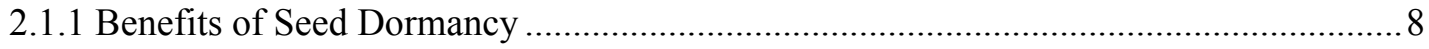

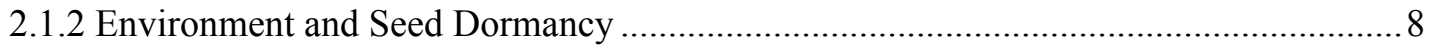

2.1.3 Seed Dormancy Across Genotypes........................................................................

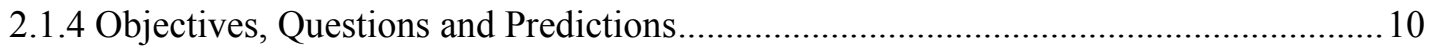

2.2 Materials and Methods .........................................................................................................12

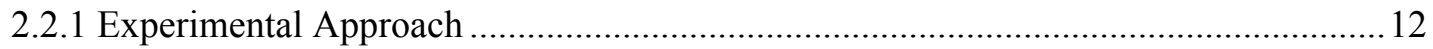

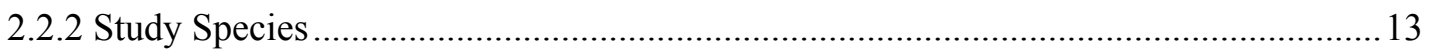

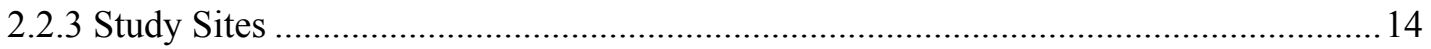

2.2.4 Seed Sources for Replicated Populations .............................................................. 14

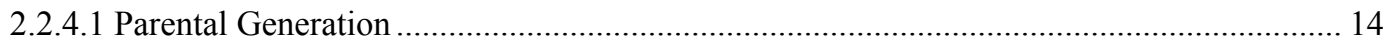

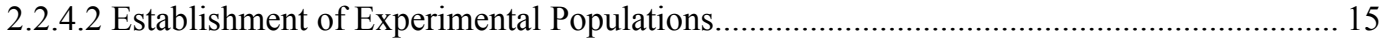

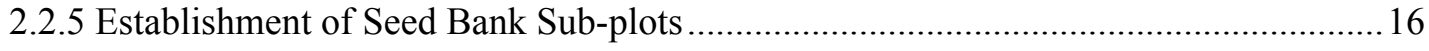

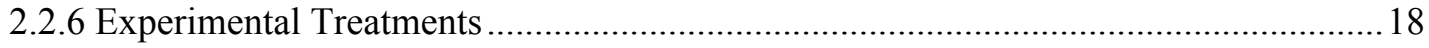

2.2.7 Effect of Watering Treatments on Soil Moisture......................................................... 19

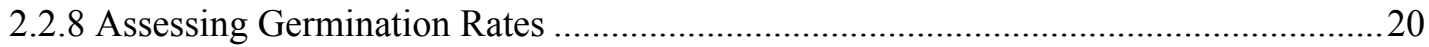




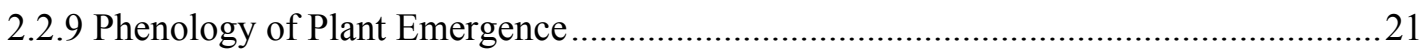

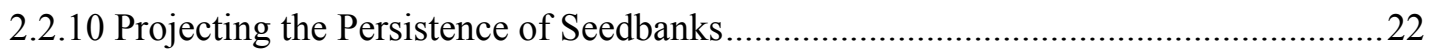

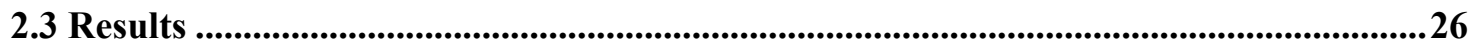

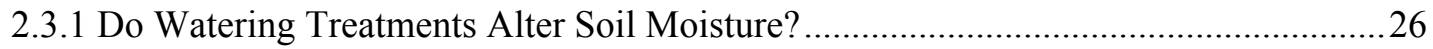

2.3.2 Do Rates of Germination, Dormancy and Mortality Vary in Response to Genotypic or

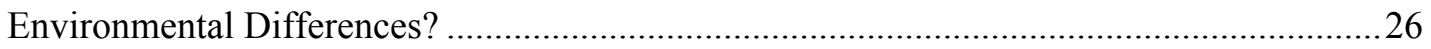

2.3.3 Does Date of Emergence or Number of Emerging Seedlings Vary Because of

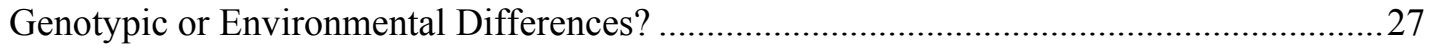

2.3.4 How will Seedbanks Persist for each Genotype and each Watering Treatment? .........27

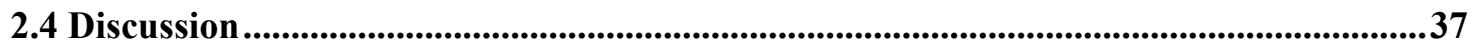

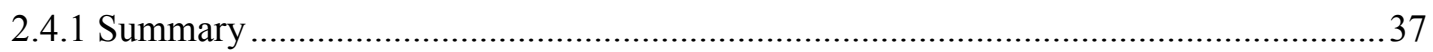

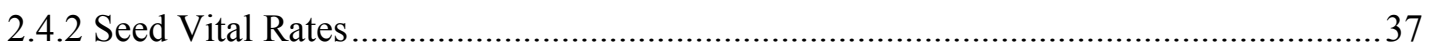

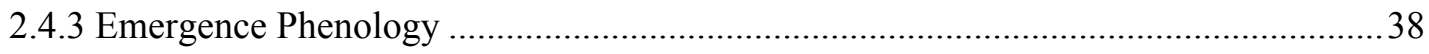

CHAPTER 3. Measuring The Relative Invasiveness Of Crop-Wild Hybrid

Raphanus Lineages Across A Precipitation Gradient Using A Life Table Response

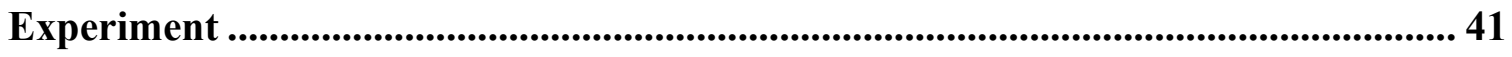

3.1 Introduction ..........................................................................................................................................4

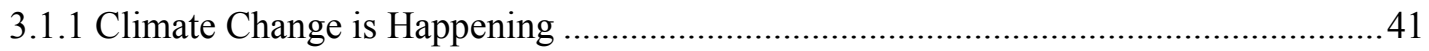

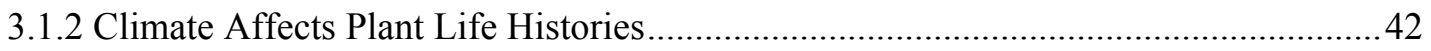

3.1.3 Expect Different Life-history Responses to Identical Environmental Cues in Crops and

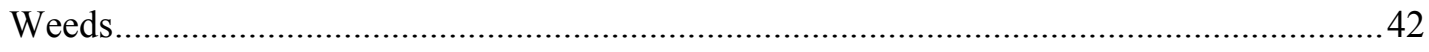

3.1.4 Objectives, Questions and Predictions.............................................................. 44

3.2 Materials and Methods ......................................................................................................45

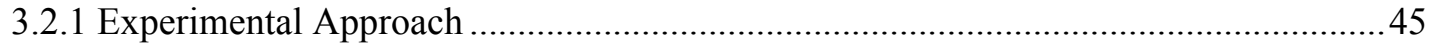

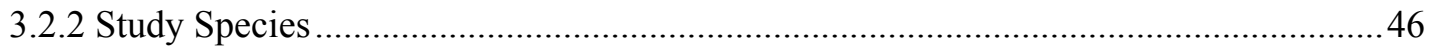




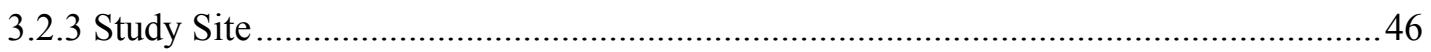

3.2.4 Seed Sources for Replicated Populations ............................................................ 47

3.2.5 Establishment of Replicated Populations ............................................................. 48

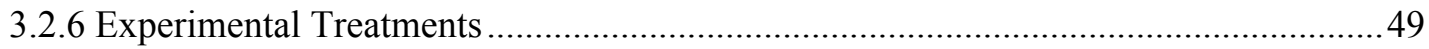

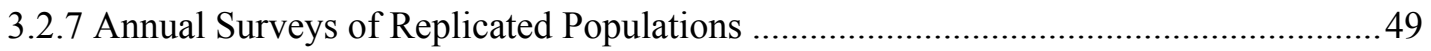

3.2.8 Weekly Surveys of Replicated Populations............................................................ 50

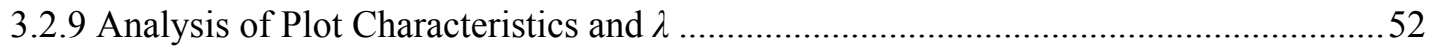

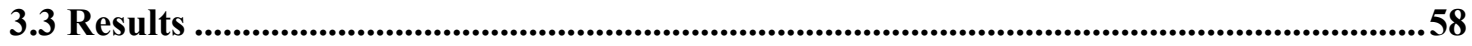

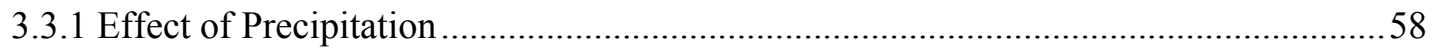

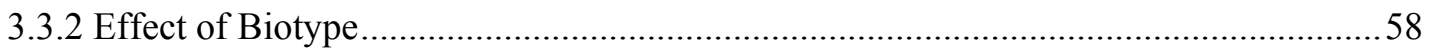

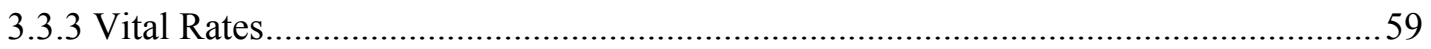

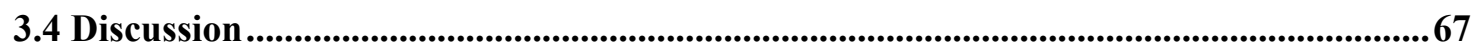

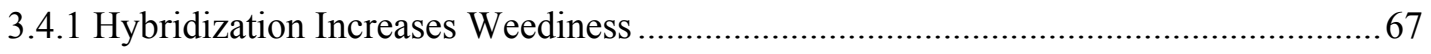

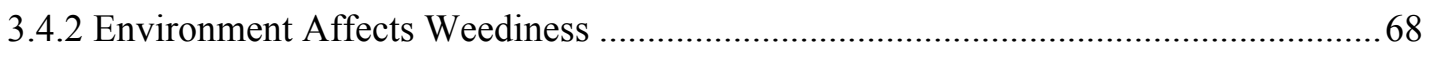

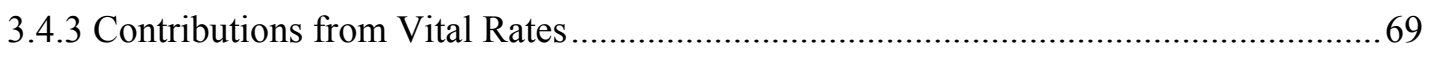

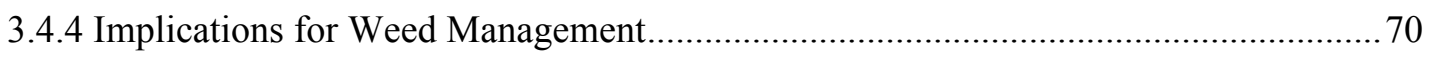

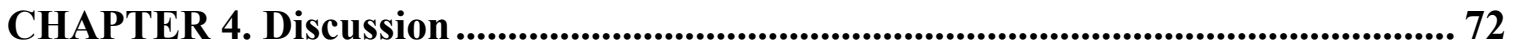

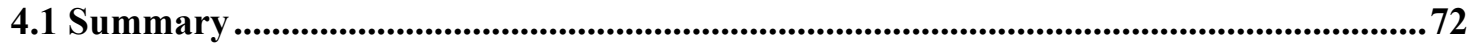

4.2 Global Agriculture Problems .......................................................................................................73

4.3 Weed-management Strategies ............................................................................................... 74

4.4 Future Work ............................................................................................................................................75

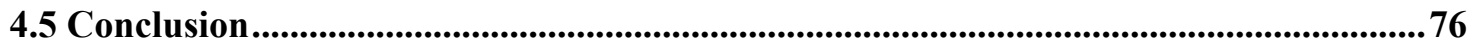

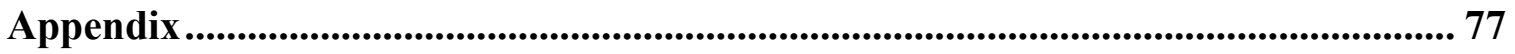

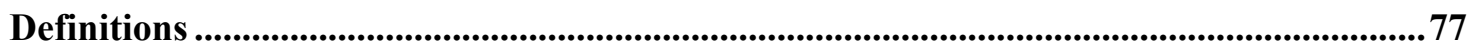

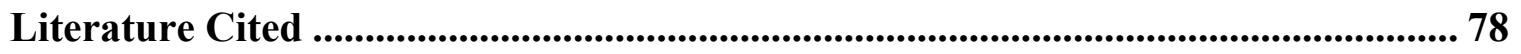




\section{LIST OF TABLES}

Table 2.3.1: MANOVA of the effects of biotype and watering treatment on trait over

three removal dates of radish seeds 28

Table 2.3.2: Average germination, dormancy and mortality rates transformed across

biotypes of Raphanus seeds, watering treatments, and removal dates

Table 2.3.3: Repeated measures ANOVA of the effects of biotype and watering treatment on Raphanus seedling emergence timing

Table 2.3.4: ANOVA with biotype and watering treatment as main effects for average date of emergence and proportion emerged in first three weeks after tilling

Table 2.3.5: Average days to emergence from tilling and proportion emerged within first three weeks from tilling across biotypes of Raphanus seeds, and watering treatments

Table 3.3.1: Repeated measures ANOVA with year as within subject effect, biotype and watering treatment as between subject effects for asymptotic population growth rate

(ג) of Raphanus 60

Table 3.3.2: Two univariate ANOVAs with biotype and watering treatment as main effects for asymptotic population growth rate $(\lambda)$ of Raphanus populations. 61

Table 3.3.3: Average population growth rate $(\lambda)$ across biotypes, watering treatments and years, for Raphanus populations

Table 3.3.4: The average values of select vital rates of $R$. raphanistrum and $R$. raphanistrum $\mathrm{x}$ R. sativus over two growing seasons under three watering treatments 


\section{LIST OF FIGURES}

Figure 2.2.1: Example of control shelter watering treatment, Summer 2013, in Koffler

Scientific Reserve, King City, ON, Canada.

Figure 2.2.2: 2,3,5 - Triphenyltetrazolium chloride stain used in seed viability test...... 25

Figure 2.3.1: Percentage volumetric water content among watering treatments 34

Figure 2.3.2: Average germination, dormancy and mortality rates among watering treatments and removal dates for wild and crop-wild hybrid seeds

Figure 2.3.3: Average days to emergence after tilling across years and biotypes of Raphanus seeds 36

Figure 3.2.1: Schematic of experimental design showing biotype and treatment assignments over year and generation for 24 plots 55

Figure 3.2.2: Layout of precipitation shelter over plot. Key materials, dimensions, and sub-sampling quadrants for flower counting are given. 56

Figure 3.2.3: Raphanus life cycle represented in matrices 57

Figure 3.3.1: Comparison of average population growth rates $(\lambda)$ averaged over years of wild and crop-wild hybrid populations of Raphanus grown under various watering treatments

Figure 3.3.2: Contributions from dormancy, germination, survival to non-flowering adult, survival to flowering, and fecundity vital rates of Raphanus, to differences between hybrid and wild biotype population growth rates $(\Delta \lambda)$, under three watering treatments 


\section{CHAPTER 1. INTRODUCTION}

\subsection{Crop-wild Hybridization and the Evolution of Increasingly Invasive Lineages}

Many species of plant pests have evolved in the same environmental contexts as their crop relatives and there is a growing need for a better understanding of weedy species’ population dynamics (Barrett 1983; Small 1984; Gould 1995; Jordan and Jannink 1997). A species of plant which thrives in its environment can become a troublesome pest for human-mediated goals in agricultural settings as well as in natural communities; known as a 'weed' and an 'invasive', respectively (Ellstrand et al. 2010). Related species or varieties can become increasingly problematic when they hybridize with crop plants and subsequently evolve novel and advantageous phenotypes (Mallet 2007). Such interspecific mating results in genetic exchange forming mixed-genotype weed populations of crop biotypes, wild biotypes, and their crop-wild hybrid offspring biotypes. These newly formed populations contain additional genetic variation, which can allow for adaptive evolution of weedier phenotypes that may be intermediate to, or exist outside, the range of phenotypes found in parental lineages (Dewet 1975; Small 1984; Campbell et al. 2006). Thus, hybridization has been hypothesized to increase the invasiveness or weediness of hybrid offspring (Ellstrand and Schierenbeck 2000), though contrary evidence also exists (Whitney et al. 2009).

Several studies have assessed the success of hybrid weed populations relative to their wild parent, (Mohler 2001). Many examples reveal that hybrid taxa contain highfitness traits (Arnold 1997; Welch and Rieseberg 2002; Ma et al. 2010), due to the transmittance of artificially selected crop traits to wild populations (Snow et al. 2003; Perez-Jones et al. 2006; Hartman et al. 2012), while others claim they are relatively less 
fit than the wild type (Stewart et al. 2003; Gutierrez et al. 2011). With hybridization inherently incurring greater heterozygosity in resulting offspring, heterosis (hybrid vigor) may be the product of an ample gene pool (Langevin et al. 1990; Klinger and Ellstrand 1994; Uwimana et al. 2012). Hybrid plants can differ from one or both of their parents in terms of phenology, growth rate, physiology, productivity, morphology and persistence. Furthermore, greater genetic variation in hybrid populations relative to their parental taxa could provide the raw material for evolutionary adaptation to local conditions. This increased variation could provide crop-wild hybrids with the ability to increase tolerance or more quickly adapt, relative to wild relatives, to the wide range of biotic and abiotic conditions that colonizing weed populations are likely to encounter (Baack et al. 2008; Hovick et al. 2012).

There are an increasing number of cases where hybrid lineages have become more invasive than their wild predecessors (e.g. Ellstrand et al. 1999; Ellstrand and Schierenbeck 2006; Mercer et al. 2006; Blair et al. 2012). The method by which one determines whether a population is more or less invasive than another is not universally agreed upon in the literature (Colautti and MacIsaac 2004). I make such assessments using population growth rate $(\lambda)$ and population persistence in a local area, though greater dispersal abilities should also be considered (Campbell et al. 2014). Hybrids can become invasive if newly acquired traits contribute to higher $\lambda$ s relative to the wild types and allow them to persist in their local environment. Traits that can have a significant impact on plant fecundity tend to be those associated with demographic life-history parameters that alter various rates of survival and reproduction. These parameters collectively contribute to $\lambda$ (Caswell 2001). Few studies have directly compared 
demographic parameters such as fecundity, survival, germination or clonal growth of hybrid taxa with that of their parents synthetically, using $\lambda$ (although see Hooftman et al. 2005). It is important to examine entire life cycles to understand how hybridization alters the invasiveness of weed populations (Bergelson 1994; Bullock 1999). Variation in the probability of germination, survival, and reproduction created by genetic diversity or environmental context can affect weed population dynamics, perhaps in unexpected ways. By using a matrix-modeling approach, I integrate life-cycle data to generate predictions of population growth and invasiveness (Parker 2000; Caswell 2001; Koop and Horvitz 2005). Wider use of experimental, comparative studies that focus on the demographic characteristics of hybrids and their parental taxa within the same environment are essential to rigorously test the hypothesis that hybridization can lead to greater invasiveness.

For plants with heightened dispersal and colonizing abilities, success may be determined by pre-existing traits that are or become favorable in their new environment (Rejmanek 2000). Alternatively, plants could evolve weedy and invasive traits that can also contribute substantially to their potential as pests in human-controlled environments (Baker 1965; Barrett 1983). A large number of these pests have evolved from their ancestors (Gressel 2005), such as hybrid radish (Raphanus sativus $x$ R. raphanistrum) lineages (Hegde et al. 2006). Many key differences in phenological, physiological, morphological, etc. traits are present between domesticated crops and their feral descendants, which have implications for interspecific competitive abilities and resulting population growth rates $(\lambda \mathrm{s})$. For example, cultivated plants are heavily selected for traits that aid in predictability and dependability of crop harvests, such as minimal seed 
dormancy compared to wild plants (Gepts 2004). I explored how such discrete evolutionary trends can interact with contextual environments as dictated by changing physical climatic conditions.

To this end, my thesis assessed the effects of a globally shifting climate on weed invasive potential. As global change progresses, abiotic environmental conditions such as temperature, precipitation, light quality and soil aeration are rapidly increasing in severity (IPCC 2012). Precipitation extremes such as drought and flooding are expected to appear with greater magnitude and regularity in certain regions (Rosenzweig et al. 2002; IPCC 2012). I experimentally simulate such projected future climate scenarios on different lineages of an invasive weed, testing for environment by genotype effects.

\subsection{Experimental Approaches}

To address the central themes and questions of this thesis, my methodology combines several crucial aspects of experimental biology. Previous work (Campbell et al. 2014) performed similar experiments with a few key differences that make this thesis conceptually and methodologically novel. In attempting to convincingly test for genetic and/or environmental differences between crop and wild biotypes, I use a natural selection experiment to assess life history and fitness parameters (Conner et al. 1996; Hierro et al. 2005; Brodersen et al. 2008). Through this experimental evolution approach, I can quantitatively tease apart the effects of environment and genetics on population growth rates. As is the case with Raphanus, testing between biotypes of an invasive species involves careful thought in regard to standardization of experimental treatments, adequate garden sample size, discretely bred genetic lineages and biosafety precautions 
(Moloney et al. 2009). I used rain-out shelters as an experimental treatment to simulate projected climate change scenarios of varying precipitation allotments (Miranda et al. 2011; Campbell et al. 2013; Xu et al. 2013; Zhu et al. 2014). Ideally, this experimental design is imposed to manipulate the amount of water applied to a given plot of land in the field by intercepting the natural rainfall into tanks for reallocation (Yahdjian and Sala 2002). This design allows for easy replication, minimal obstruction of light, and a low cost. Limitations to this approach involve mild light obstructions and uneven distributions of soil moisture in a plot due to edge spray.

Seed germination and seed dormancy play a crucial factor in a plant's life history and thus in determining relative lifetime success (Baskin and Baskin 2001), especially affecting the persistence of populations in new and ecologically severe habitats, competition within and between species (Cheplick 1996), and consequent fecundity (Cohen 1968). Variation in the physical environment will affect long-term seed bank dynamics by selecting for complementary germination, dormancy and mortality rates between wild and crop-wild hybrids (Venable 1989; Rees and Long 1992; Schroder and Prasse 2013). This shift can greatly influence the relative success of co-occurring biotypes and, thus, evolutionary trajectories of plant populations (Rees and Long 1992; Mercer et al. 2006). Seed status (germinated, dead, or dormant) is a demographic parameter that is relatively understudied because of the difficulty in assessing below ground germination and mortality in nature. Seed burial experiments allow researchers to track of the germination and dormancy of individual seeds in a natural environment (Mercer et al. 2006; Presotto et al. 2014). By removing seeds for assessment over a wide range of time, seeds show more complex and dynamic life-history strategy than if I score 
all seeds at one snapshot in time. Upon each removal date, seed sacs were scored for differences in fruit/seed number from what was buried, seeds that germinated and seeds that are clearly dead. Of the remaining seeds, I determined their current viability by employing standard laboratory tetrazolium tests specific to Raphanus (Patil and Dadlani 2009). Variation in germination and dormancy traits among populations commonly occurs within plant species due to genotypic differentiation, environment and local adaptation (Linhart and Grant 1996), so I expect seed bank dynamics to be critical to differences between hybrid and wild $\lambda$ s from various environmental lineages.

\section{$\underline{1.3 \text { Study System: Wild radish }}$}

Both wild radish (R. raphanistrum or jointed charlock) and cultivated radish $(R$. sativus) are native to Europe and were introduced to California in the 1800s (Panetsos and Baker 1967). Both taxa are annual (in temperate climates), insect-pollinated, selfincompatible and will spontaneously mate to form hybrid offspring ( $R$. raphanistrum $x R$. sativus) (Snow et al. 2001). Because hybrids go through a reciprocal translocation process (genetic recombination between nonhomologous chromosomes), $\mathrm{F}_{1}$ hybrids will abort over half of their pollen grains, thus potentially reducing their ability to reproduce and hence their potential weediness. However, natural populations of advancedgeneration hybrid Raphanus are fecund and hearty, invading natural dune systems on the coast of California and neighbouring agricultural fields (Panetsos and Baker 1967). The two species differ in a number of life-history traits: $R$. raphanistrum has earlier emergence, bolting, flowering and fruiting; increased seed dormancy and genetic diversity, greater flower, fruit and seed number relative to R. sativus (Holm et al. 1997; 
Warwick and Francis 2005; Ellstrand et al. 2010). As well, the two species differ in a number of significant morphological traits: R. sativus has white, pink or purple flowerpetals, an enlarged, edible hypocotyl and soft, easily crushed fruit. In contrast, $R$. raphanistrum is commonly yellow flower-petal coloured, has a small inedible taproot, and has a hard and woody silique (Snow et al. 2001; Ellstrand et al. 2010). Wild radish is an extremely problematic agricultural weed in over 65 countries (Holm et al. 1997). In California, their geographic distribution quickly segregated such that populations with predominantly $R$. raphanistrum characters appear inland and populations with predominantly R. sativus characters appear in coastal areas (Panetsos and Baker 1967). Thus, the two species may have discrete geographical niches described by their physiological tolerances. The following body of work uses this fundamental piece of information as an impetus for predicting how future habitats will enhance or deter weed infestations. 


\section{CHAPTER 2. SEED DORMANCY AND GERMINATION OF WILD AND CROP- WILD HYBRID RAPHANUS ACROSS A SOIL MOISTURE GRADIENT}

\subsection{Introduction}

\subsubsection{Benefits of Seed Dormancy}

The ability for seeds to lie dormant in soil (i.e., temporarily delay germination) over multiple growing seasons is integral to plant, and specifically weed, population persistence (Verdu and Traveset 2005). In agricultural contexts, delayed germination and dormancy allows populations to avoid post-emergent herbicides (Forcella 1998) and competitive crop rotations and withstand drought (Vegis 1964; Koller 1969; Baskin and Baskin 1974; Pnueli et al. 2002). Plants have evolved several widespread and interacting mechanisms to promote seed dormancy (Baskin and Baskin 2004; Finch-Savage and Leubner-Metzger 2006), including physiological dormancy (Adkins et al. 1984), morphological dormancy (Jacobsen and Pressman 1979), physical dormancy (Baskin 2003), and combinations thereof (Hepher and Roberts 1985). Such mechanisms permit seeds to detect when environmental conditions are favourable for germination and subsequent plant viability. Environmental cues as well as adaptive genetic factors regulate plant emergence, and thus the intensity of weed infestations.

\subsubsection{Environment and Seed Dormancy}

Many environmental variables affect the likelihood seeds remain dormant, potentially extending the longevity of weed infestations (Thompson and Grime 1979). Temperature requirements primarily influence seed deterioration, dormancy, and germination (Stokes 1965; Duddu and Shirtliffe 2014). In some species, extreme heat 
from fire burns may decrease rates of dormancy (Ruyle et al. 1988; Zammit and Zedler 1988). As well, light quality penetrating, and oxygenation of soil can influence both seed dormancy and germination dynamically throughout seed development (Roberts 1962; Evenari 1965). Finally, water availability in the maternal environment (Peters 1982; Arnold et al. 1992; Eslami et al. 2010) as well as in the mature seed's environment and its controlled uptake into the embryo (Roberts 1962; McIntyre and Hsiao 1985) strongly influence germination and dormancy rates. Non-dormant seeds will imbibe water faster than dormant seeds (Hou et al. 1997), especially when mechanical injury to the seed coat allows water to penetrate (Raju et al. 1986). In some species, soil moisture is required to wash chemical inhibitors from seed surfaces (Baskin and Baskin 2001). In contrast, some Brassicaceae including Raphanus retain their dry silique at dispersal and germination is delayed until water can soak through the silique and induce imbibition in the protected seed (Cousens et al. 2010). Soil moisture, as well as temperature, light quality and soil aeration are now changing in location, frequency and magnitude with progressing global change (IPCC 2012). Long-term models project rises in precipitation extremes over terrestrial systems, with many locations projected to experience drought intensification or more frequent flooding, increased temperatures, poorer light quality due to increased cloud coverage and reduced soil aeration due to flooding (Rosenzweig et al. 2002; IPCC 2012).

\subsubsection{Seed Dormancy Across Genotypes}

Seed germination in Raphanus raphanistrum (wild radish or jointed charlock) an annual weed, is stimulated by the removal of its hard silique and seed coat (Cheam 1986; 
Young 2001). Seed germination in cultivated radish (R. sativus) is comparatively easier since water can more easily penetrate the soft silique walls and break dormancy (Schopfer and Plachy 1993; Snow and Campbell 2005). Germination in both species could be faster with increased water availability if additional water sped silique degradation (Eslami et al. 2006). Despite potentially reduced dormancy with higher soil moisture, seedling emergence may also decline as soil becomes increasingly inundated. The effect of flood conditions on Raphanus may be detrimental to seedling survival and emergence from the soil while still promoting dormancy breakdown.

The extent to which environmental cues can regulate germination and dormancy differs heritably between crops and their wild relatives (Naylor and Jana 1976) as a consequence of different selection environments (Linhart and Grant 1996). Often, domestication selects for low seed dormancy and rapid germination in crops (Seiler 1992); in contrast, weed populations often experience selection for delayed germination

or prolonged dormancy (Teo-Sherrell 1996). For instance, germination was significantly higher and dormancy was significantly lower in crop-wild hybrid sunflowers (Helianthus annuиs) than in weedy plants as a result of domestication genes inherited by crop-wild hybrid plants from crop parents (Mercer et al. 2006). These results suggest that crop allele introgression could increase in environments where wild seeds tend to have high dormancy and where crop-wild hybridization introduces rapid germination traits, although this prediction requires additional complementary tests of fitness.

\subsubsection{Objectives, Questions and Predictions}


Co-occuring populations of cultivated and wild Raphanus will readily hybridize to generate populations of hybrid offspring with potentially enhanced weedy traits. Wild (R. raphanistrum) and crop-wild hybrid (R. sativus $x$ R. raphanistrum) populations of radish can exhibit distinct demographic vital rates after less than three generations of natural selection (Campbell et al. 2014); however, these predictions of asymptotic population growth rates $(\lambda)$ failed to incorporate seedbank dynamics. Here, I tested whether environments with extreme soil moisture content may induce delayed emergence of hybrid seeds relative to their wild progenitors. Below, to improve my ability to predict the consequences of changing precipitation on the weediness of wild radish populations, I measured rates of seed dormancy, germination and mortality of seven wild and eight crop-wild hybrid populations. To assess how seedbank dynamics may change with moisture conditions, I asked the following questions:

(1) Do rates of germination vary with genotype or environment?

(1a) Are there differences in germination rates between wild and crop-wild hybrid populations? I predict that relative germination and dormancy rates are genetically controlled, with hybrid seeds germinating more often than wild seeds. (1b) Are there differences in germination rates between populations that experience manipulated $v s$. unmanipulated soil moistures? I expect drought conditions to increase seed dormancy and lower rates of germination, especially for wild seeds.

(2) Does date of emergence vary because of genotypic or environmental differences? 
(2a) Are there differences in date of emergence between wild and hybrid populations? I expect crop-wild hybrid plants to emerge earlier than wild plants, with less variation in emergence date in crop wild hybrid plants.

(2b) Are there differences in date of emergence between populations that experience higher or lower soil moistures than in nature? I predict drought conditions will delay emergence dates, especially for wild seeds.

(3) How will seed banks persist for each genotype and each watering treatment?

I predict seed banks of wild, high-precipitation populations will persist in a locale for longer than seed banks hybrid, low-precipitation populations.

\section{$\underline{2.2 \text { Materials and Methods }}$}

\subsubsection{Experimental Approach}

I assessed below-ground seed bank dynamics over 18 months in an experimental field study. I grew seeds of wild radish (Raphanus raphanistrum) and crop-wild hybrid radish ( $R$. raphanistrum $x R$. sativus) populations across a gradient of soil moistures. I then collected and selectively labeled seeds with written tags in mesh sacs for tracking before burying them in their maternal environment. I periodically removed seeds from the ground over three time periods. Upon removal, I scored seeds as dead, germinated or dormant using a tetrazolium seed viability stain. Then, I measured the effect of moisture environment and genotype on frequencies of mortality, germination, dormancy and emergency patterns. Further, I projected seed bank persistence under three climatic scenarios. 


\subsubsection{Study Species}

Although both plants are panmictic, Raphanus raphanistrum is an economically damaging weed in many grain crops (Holm et al. 1997) whereas $R$. sativus is grown for its enlarged hypocotyl, edible fruits or as a tillage plant (Snow and Campbell 2005). Raphanus raphanistrum was introduced to California in the mid-1800s where it hybridized with cultivated radish to form a third stable lineage (Hegde et al. 2006), sometimes termed the California wild radish or, confusingly, $R$. raphanistrum (Panetsos and Baker 1967). Both species are self-incompatible, insect-pollinated, and readily hybridize (Snow et al. 2001). Here, I distinguish the three lineages or 'biotypes' as wild $R$. raphanistrum, crop $R$. sativus, and the hybrid $R$. raphanistrum x sativus. Petal colour of the cultivated $R$. sativus ranges from white to pink/violet, while the wild $R$. raphanistrum has a petal colour of yellow or bronze (pink overlaid on yellow) (Panetsos and Baker 1967). I used this petal colour morphology to identify the genotype of plants (wild radish or crop-wild hybrid radish).

Wild radish is difficult to control because of its early emergence, genetic diversity, seedbank longevity, and long-term seed dormancy (Cheam and Code 1995; Kercher and Conner 1996; Holm et al. 1997; Warwick and Francis 2005). Viable R. raphanistrum seeds below-ground can lie dormant for several years due a thick silique wall that prevents germination-inducing imbibition (Reeves et al. 1981); large seeds and those seeds found within thick-walled fruit tend to germinate later than small seeds or those seeds within thin-walled fruit (Eslami et al. 2010). Further, dormancy in Raphanus spp. is, at least partly, genetically determined (Cheam 1986); spring emergence of seedlings is 
earlier and seed dormancy greater in R. raphanistrum than R. sativus (Warwick and Francis 2005; Ellstrand et al. 2010).

\subsubsection{Study Sites}

The parental generation $\left(\mathrm{F}_{0}\right)$ was grown in 2010 at the Ohio State University's Waterman Farm, Columbus, OH USA $\left(40^{\circ} 0{ }^{\circ} \mathrm{N}, 83^{\circ} 1^{\prime} \mathrm{W}, 232 \mathrm{~m}\right.$ asl). This research station is situated in a temperate climate with total annual precipitation reaching $921 \mathrm{~mm}$ and an average July temperature of $25.0^{\circ} \mathrm{C}$ in 2010 (National Weather Service data for 2010: http://www.weather.gov/). Following generations $\left(F_{1}-F_{3}, 2011-2013\right)$ were grown

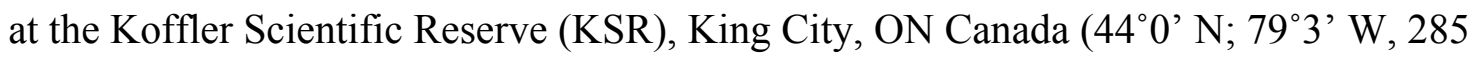
$\mathrm{m}$ asl). Located in the Oak Ridges Moraine; a region of headwaters, rolling hills and valleys, this 348 -hectare research station is composed of pasture and woodland sites and exposed to natural weather conditions, herbivory and pollinators. This research station is also situated in a temperate climate region with total annual precipitation that reached $833.1 \mathrm{~mm}$ (minus December; missing data) and 37.2mm in May 2012; and $1026.7 \mathrm{~mm}$ annually and $80.9 \mathrm{~mm}$ in May 2013. The region had an average July temperature of $23.5^{\circ} \mathrm{C}$ and $21.8^{\circ} \mathrm{C}$ for 2012 and 2013, respectively (data from Buttonville, ON, $24 \mathrm{~km}$ SE of KSR, Environment Canada: http://climate.weather.gc.ca/). Field sites moved from Ohio to Ontario when the Campbell Lab relocated to Ryerson University, Toronto, ON Canada. The experimental design of the larger project remained relatively similar between the two sites.

\subsubsection{Seed Sources for Replicated Populations}

\subsubsection{Parental Generation}


Wild radish ( $R$. raphanistrum) seeds were haphazardly collected by selecting fruit from 60 plants with yellow flower color (a homozygous recessive trait) across three field populations near Binghamton, NY USA (Conner et al. 1996). From this collection, a population ( $>200$ plants) was grown for several generations in a greenhouse in East Lansing, MI USA (Conner et al. 1996). The crop radish cultivar (Red Silk, Harris-Moran Seed Co., Modesto, CA, USA), was homozygous for white flower colour, and the R. raphanistrum population was homozygous for yellow flower color.

As in Pirimova et al. (in press), I transplanted 40 populations of cultivated and wild plants (nine cultivated and nine wild seedlings per plot) into plots at Waterman Farm during the spring of 2010. I planted seedlings in one of four watering treatment plots in a completely randomized block design with one plot per treatment, per biotype, per block, making five blocks. Plots were separated by at least $200 \mathrm{~m}$ to reduce pollen contamination, though crop-wild gene flow can rarely occur at greater distances (Klinger et al. 1991). In addition to wild and cultivated radish, each plot also contained nine Helianthus annuus and nine Helianthus petiolaris plants in a clustered design (Sneck 2012). I planted seedlings of each species in three rows of three plants each, with approximately $30 \mathrm{~cm}$ of spacing between plants. Naturally occurring pollination allowed for the mating between $R$. raphinistrum and R. sativus to create the crop-wild hybrid biotype. I collected seeds only from wild radish mothers for experimental use as the $F_{1}$ generation in 2011.

\subsubsection{Establishment of Experimental Populations}


In 2011, I established 24 plots of $F_{1}$ wild and crop-wild hybrid radish in the field at KSR from seeds produced in 2010. All plots were a minimum distance of $40 \mathrm{~m}$ from each other to minimize pollen contamination among plots (Ellstrand and Marshall 1985). Due to the considerable variation in physical characteristics (i.e., elevation, slope, soil quality, proximity to tree cover) among plot sites, I used a randomized complete block design with three blocks, each containing one plot per treatment combination. On average, plots within a block were spatially clustered more than plots among blocks. Plots were $2.44 \mathrm{~m}$ by $3.05 \mathrm{~m}$ in area, marked by four corner posts. Plots were tilled during the third and fourth week of May in 2011 and 2012 and during the third week of May in 2013.

Seeds of the $F_{1}$ generation (produced during the 2011 field season) were germinated and grown to seedlings in a KSR greenhouse before field transplanting. In each plot, 117 randomly selected seedlings were planted. Petal colour was recorded when plants flowered; plants with yellow petals were recorded as wild biotype, and plants with white petals were recorded as hybrid biotype. Within a block, they randomly assigned plots to a biotype treatment; any plant with petal colour contrary to the plot's assigned biotype was removed upon discovery. Flowering plants fruited and senesced naturally such that their seeds fell on the plot, to produce the $F_{2}$ generation in 2012 .

\subsubsection{Establishment of Seed Bank Sub-plots}

During the Summer and Fall of 2012, I harvested $F_{3}$ seeds from the $2012 \mathrm{~F}_{2}$ generation as plants senesced (defined as when a plant stopped producing flowers and when many fruits dehisced when touched gently). Seeds from all remaining plants were collected at the last weekly census (Oct. 18, 2012, after the first hard frost), when there was no new fruit development on any plants (L. Campbell, pers. obs.), regardless of plant 
maturity. Above-ground plant material was stored, including any attached fruit, in paper bags and dried in a drying oven for a minimum of seven days at $30^{\circ} \mathrm{C}$.

Third-generation seeds were used in this seed burial experiment. For the two years leading up to, and the duration of the seed burial experiment, plant lineages remained within a single plot location at my KSR site, except for the period between the Fall 2012 harvest and Winter 2012 seed burial when seeds were collected and repackaged. I collected, counted and distributed $\mathrm{F}_{3}$ seeds as whole fruits only (pods were never broken up to divide seeds to avoid inadvertently altering dormancy) from any collected plants with an adequate supply of seeds. Each plant had to contribute at least 10 seeds (max. 30 seeds, from no more than 15 fruits and no less than six fruits). From each plant, I randomly selected ten fruits that possessed at least two seeds per silique and no more than five seeds per silique, to reduce variation due to maternal effects (Mazer 1987). I estimated the number of seeds within a fruit by counting the number of locules per silique by sight and touch. Thirty seeds per plant were divided into three sacs of ten seeds each. Each sac was assigned to a tray subject to one of three removal dates: Spring 2013, Fall 2013 and Spring 2014. If a plant had less than 30 seeds, or an incorrect combination of seeds/pod to create three sacs of ten seeds each, then only two sacs of ten seeds were packaged. If a plant had less than 20 seeds, only one sac was packaged.

I sewed fruits into $\sim 15 \mathrm{~cm}$ by $9 \mathrm{~cm}\left(40 \mathrm{~cm}^{2}\right)$ charcoal fiberglass screen mesh sacs (PHIFER Incorporated, Tuscaloosa, AL USA) using standard thread and a sewing machine. I assigned 9-16 seed sacs to each plastic germination tray (\#1020 with holes, Mondi, Vancouver, BC, Canada); three trays were assigned to each plot and within them 9-16 mothers were represented in a total of 29-48 sacs. All plants that comprised three 
sacs had one sac distributed per tray. Plants that comprised only one or two sacs were given to a tray or two different trays at random, respectively. Equal numbers of sacs \pm 1 were distributed to each tray. Seed sacs were haphazardly shuffled within a tray to evenly space them out.

Trays were placed back into their maternal plots between November 1 and December 7, 2013. All three trays were planted adjacent to one another in a partitioned subplot in the southwest corner of the plot. I buried the trays beneath the soil, such that seeds were approximately $6 \mathrm{~cm}$ deep. A white tag, approximately $10 \mathrm{~cm}$ high, indicated the removal date for each tray. I randomly assigned removal dates and tray location.

The seed collection in 2011 limited sample size of this experiment. Only 15 of the original 24 plots contained enough mothers with an adequate quantity of seeds to be used. As a result, I did not have enough seeds from CU plots to create sacs. Therefore, I only used 15 plots and could not assess the effect of shelter on seed-specific vital rates.

\subsubsection{Experimental Treatments}

Four watering treatments were imposed from June 4 - August 31, 2012 and June 10 - September 6, 2013. To control rainfall, I built rainout shelters, designed to maximally intercept and collect rainfall on my plots. Roofs of translucent, corrugated poly plastic (Waldo \& Associates, Toledo, OH USA) were attached to wooden frames of $3.05 \mathrm{~m}$ by $2.44 \mathrm{~m}$ for 2010 - 2012 field seasons, and roofs of transparent sheet plastic ( 3 mil, Canadian Greenhouse Suppliers, Niagara-on-the-Lake, ON Canada) were stretched over wooden frames of $3.05 \mathrm{~m}$ by $2.44 \mathrm{~m}$ for the 2013 field season. Frames were slanted, and elevated $1.2 \mathrm{~m}$ above the ground at their lowest corner with metal poles. Slanted frames were intended to intercept and divert natural precipitation into a collection barrel 
of $208 \mathrm{~L}$ capacity (approximately the amount of rain collected during the seasons heaviest rainfall), via a gutter attached to the lowest side of the frame. Shelter roofs were all oriented in a consistent NW facing direction. Collected rainwater was applied to plots often within 48 hours of a precipitation event (and no later than seven days, when mechanical difficulties arose). To minimize interspecific competition from perennial weeds, I removed perennial weeds from plots when noticed.

The four watering treatments (Pirimova et al. in press) were applied as follows:

a) Control Unsheltered (CU): To assess the effects of natural precipitation, rainwater fell naturally on unmanipulated plots;

b) Control Shelter (CS): To assess the effects of rainout shelters, the rainwater collected from CS plot shelters was reapplied onto the same plot. Collected precipitation was distributed only once the barrel was approximately $>3 / 4$ full;

c) Low Rain (LR): To assess the effects of reduced precipitation, collected rainwater was withheld. Small amounts of rain may have fallen on the plot from the open sides of the shelter;

d) Double Rain (DR): To assess the effects of increased precipitation, DR plots received twice the normal rainfall. DR plots received rainwater collected from their shelter and rainwater collected from LR plots within the same block.

\subsubsection{Effect of Watering Treatments on Soil Moisture}

Weekly, I measured the volumetric water content (\%) of the soil of each plot (June 19 - August 29, 2012; June 7 - September 8, 2013). Using a soil moisture reader (Field Scout, TDR 100/200 Spectrum Technologies Inc, Plainfield, IL USA), I took three 
haphazardly located probe recordings per plot. To assess the effect of the watering treatment on soil water content, I averaged the three $\% \mathrm{VWC}$ readings taken on a given day and analyzed the data using a repeated-measures ANOVA, with watering treatment and block as fixed effects, their interaction included in the model, and sampling date as the within-subjects repeated measure.

\subsubsection{Assessing Germination Rates}

I removed trays of seed sacs in Spring 2013 (May 27), Fall 2013 (October 20) and Spring 2014 (May 15). Seeds were kept moist in paper or Ziploc bags and refrigerated at $4^{\circ} \mathrm{C}$ for 1-7 days until scored. I removed seeds from fruit with pliers when fruit walls were tough or fingers otherwise. I would make a small nick in each seed using a sharp bladed scalpel before applying pressure between fingertips to rub off the seed coat. I immediately scored seeds that were decomposing (unusually soft or thoroughly blackened) as dead. I then scored seeds that were germinated at the time (a radical was visible or further growth) as germinated. I stained the remainder to determine viability (described below).

I imbibed seeds for 18 hours in a closed Petri dish on moistened paper at room temperature. I then applied 1-2 drops of $0.5 \%$ solution 2,3,5 - triphenyl tetrazolium chloride to each seed for 24 hours at room temperature (Patil and Dadlani 2009). After staining, I visually scored seeds as either viable or dead; weak non-viable tissues appeared mottled, purplish, brownish, or grayish red, and viable seeds appeared to have their red colour intensity change gradually across the seed with no distinct borders (Patil and Dadlani 2009). 
I treated cumulative frequency of germination, dormancy and mortality within a seed sac as a continuous variable (although it is pseudo-continuous, in reality) and, therefore, performed parametric analyses. I calculated germination, dormancy, and mortality frequencies within sacs as the fraction of the number of seeds germinating, dormant or dead as a function of the total seeds in a sac and averaged across mothers within a plot. I transformed these frequencies using the formula

$$
p^{\prime}=\frac{1}{2}\left(\arcsin \sqrt{\frac{X}{n+1}}+\arcsin \sqrt{\frac{X+1}{n+1}}\right), \text { a slight modification of Freeman and Tukey (1950) }
$$

transformation. Although one might normally use a repeated measures ANOVA approach to assess effects of watering treatment and genotype on seed bank dynamics, there is a lack of expected linearity over time among the three removal dates (Spring rates vary from Fall rates irrespective of time since burial), and there is dependence among seed traits (germination, dormancy and mortality rates). Thus, I ran three MANOVAs (one for each removal date: Spring 2013, Fall 2013 and Spring 2014), in which trait was a multivariate effect, and biotype, watering treatment and block were between-subject main effects.

\subsubsection{Phenology of Plant Emergence}

In sub-plots within the experimental plots, I conducted weekly censuses between May 25 - October 18 in 2012, and June 6 - October 25 in 2013 to record emergence. Within 1-16 days of tilling, I established central sub-plots of $1 \mathrm{~m}^{2}$. I intended to follow approximately 50 plants per subplot, but subplot plant density varied among plots. When more than 50 seedlings emerged from the soil within a subplot, I reduced the size of the subplot by consistently reducing the subplot on one side until the sub-plot again 
contained approximately 50 plants again. Emerged Raphanus seedlings were classified as any plant with cotyledons growing above the soil. I censused sub-plots for seedling emergence weekly and date of emergence was calculated as the number of days between tilling the soil within plots and emergence. Within a plot, average days to emergence, as well as proportion emerged within first three weeks since tilling was calculated.

To assess whether biotype and watering treatment have an effect on the phenology of seedling emergence, I ran two repeated measures Type III mixed model ANOVA with average days to emergence after tilling as a response variable; biotype, watering treatment, and block (and their interactions) as fixed effects; and year as the repeated measure. I ran four Type III mixed model ANOVAs for each year (2012 and 2013), with average days to emergence after tilling as response variables; biotype, watering treatment and block as fixed effects. When block had no significant effect, it was removed from the model. Average days to emergence was natural logarithm transformed, and proportion emerged within first three weeks after tilling was arcsine transformed to satisfy model assumptions.

\subsubsection{Projecting the Persistence of Seedbanks}

Based on the information gained in the above experiment, I explored the consequences of water availability on the persistence of seedbanks. To estimate the persistence of seedbanks, I created a theoretical seedbank of 100,000 seeds for each population with recorded data. Other iterations with starting populations of smaller orders of magnitude showed similar results. In each modeled year, the seedbank experienced seedbank losses to emergence and mortality (leaving dormant seeds only) as recorded by 
the above dataset. The first year populations experienced seedbank losses corresponding to their Spring 2013 dormancy rates, whereas all subsequent years experienced losses corresponding to Spring 2014 rates; Fall 2013 data were not used due to confounding seasonal variation in vital rates. I prevented seeds that emerged from contributing to the seed bank, so that I could make the most conservative estimates of seedbank persistence (i.e. the best-case scenario). Iterations in this model continued, based on the projected ratios of germination, death and dormancy until there were no more seeds left in the seedbank. The time until depletion of the seedbank was noted and I used it to describe the persistence of the seedbank. A Poisson distributed Type III mixed model ANOVA, with biotype and watering treatment (and their interaction) as fixed effects, and years until depletion as the response variable. All parametric tests were done using SPSS Statistics 21 (1989, 2012; SPSS Inc., Chicago Illinois USA). 


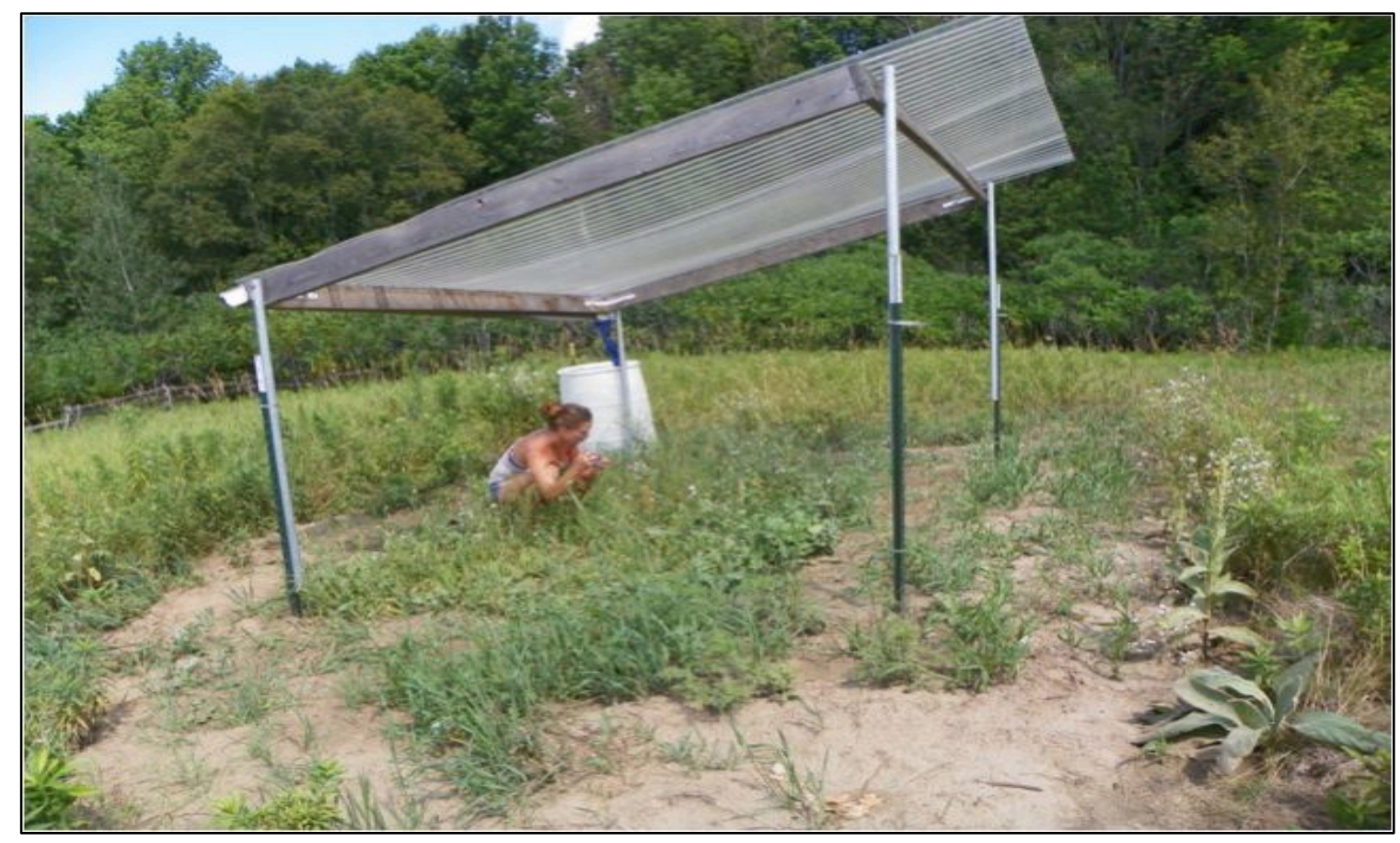

Figure 2.2.1: Example of control shelter watering treatment, Summer 2013, in Koffler Scientific Reserve, King City, ON, Canada. 


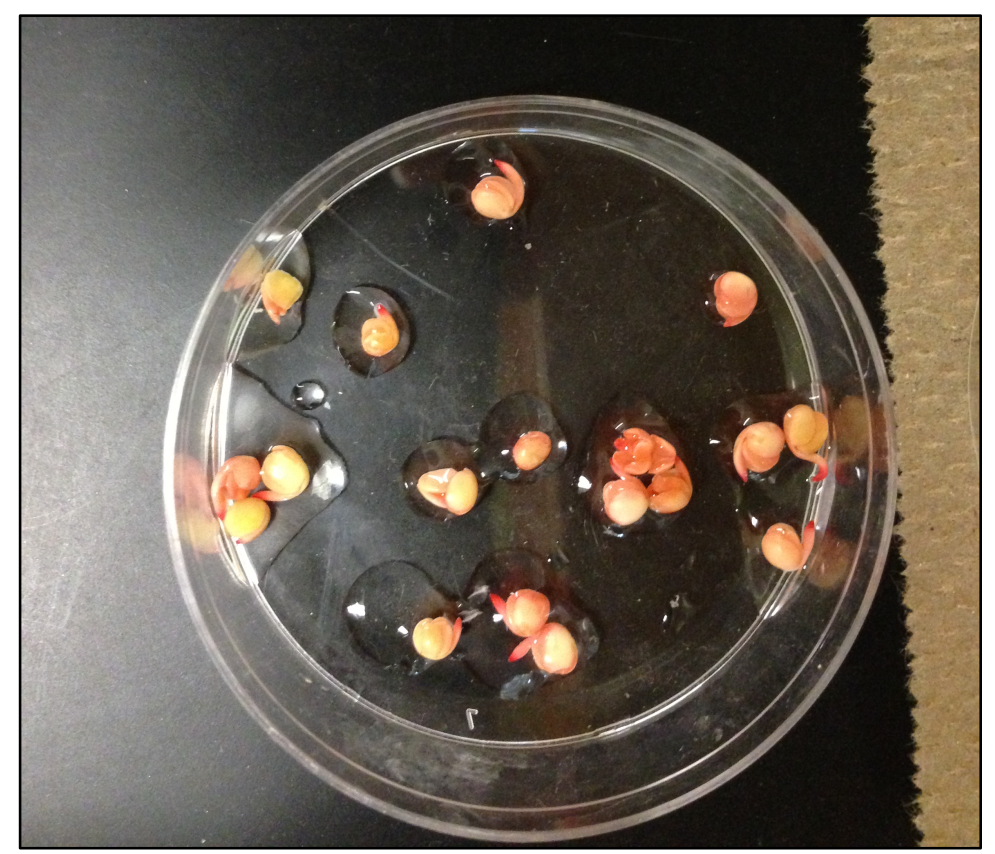

(A)

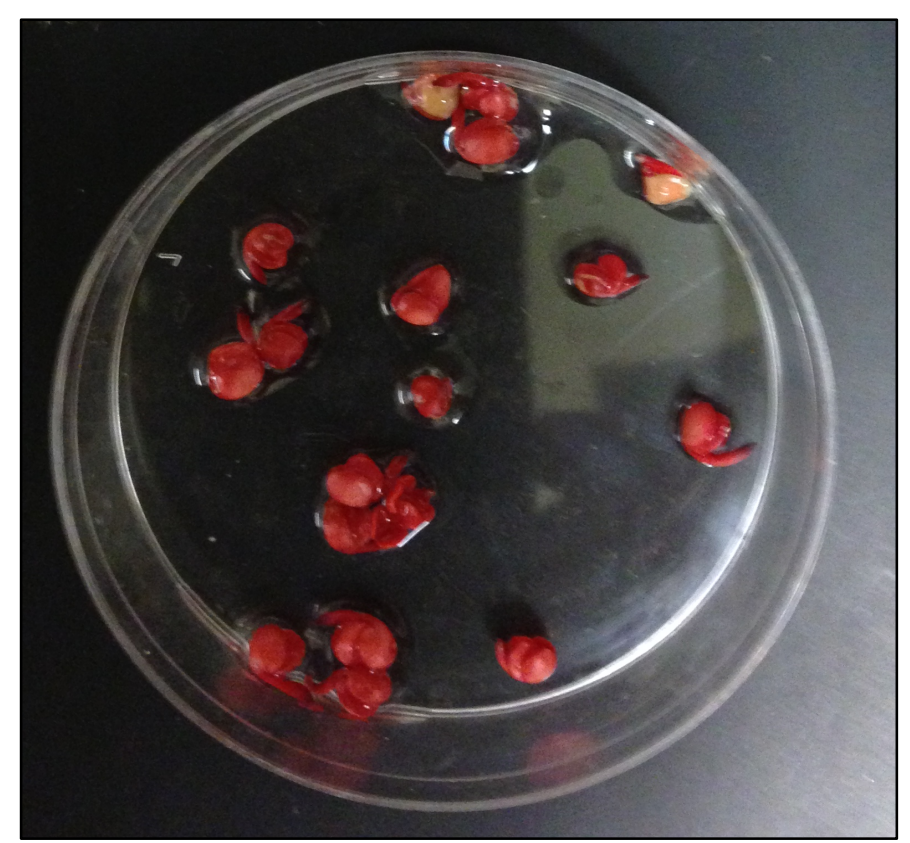

(B)

Figure 2.2.2: 2,3,5 - Triphenyltetrazolium chloride stain used in seed viability test. Most of the seeds in example (A) appeared to be weak or non viable from their dull grayish-red staining, whereas most of the seeds in example (B) appeared to be viable with bright red intensity and gradual colour shifts. 


\section{$\underline{2.3 \text { Results }}$}

\subsubsection{Do Watering Treatments Alter Soil Moisture?}

Watering treatments predictably altered soil moisture content in 2012 $\left(\mathrm{F}_{3,12}=100.880, \mathrm{P} \leq 0.000\right)$ and $2013\left(\mathrm{~F}_{3,11}=3.712, \mathrm{P}=0.046\right)$. In 2012, DR plots were significantly wetter than CS plots, which were significantly wetter than CO plots, which were significantly wetter than LR plots (Figure 2.3.1). In 2013, DR plots were significantly wetter than LR plots but CU and CS plots were not significantly different than any other plots (Figure 2.3.1). Soil moisture varied significantly across the season in $2012\left(\mathrm{~F}_{10,120}=55.333, \mathrm{P} \leq 0.00\right)$ and in $2013\left(\mathrm{~F}_{13,143}=91.399, \mathrm{P} \leq 0.000\right)$. Also, in 2012, soil moisture was significantly affected by block $\left(\mathrm{F}_{2,12}=5.519, \mathrm{P}=0.020\right)$, as well as its interaction with watering treatment $\left(\mathrm{F}_{6,12}=6.889, \mathrm{P}=0.0002\right)$.

\subsubsection{Do Rates of Germination, Dormancy and Mortality Vary in Response to Genotypic or Environmental Differences?}

Mortality rates were significantly higher than germination and dormancy rates for each removal date (Table 2.3.1). I observed a trait by biotype effect in Spring 2013 only, in which hybrid populations had greater germination rates than wild populations, but lower dormancy and mortality rates (Table 2.3.1). Germination rates were $25 \%$ higher in Spring 2014, relative to those removed in Fall 2013 (Figure 2.3.2, Table 2.3.2). Conversely, dormancy was 31\% higher in seed sacs removed in Fall 2013 than in those removed in Spring 2014 (Figure 2.3.2, Table 2.3.2). 


\subsubsection{Does Date of Emergence or Number of Emerging Seedlings Vary Because of Genotypic or Environmental Differences?}

Emergence was significantly delayed in 2012 relative to the emergence dynamics observed in 2013 (Figure 2.3.3, Table 2.3.4). Biotype (hybrid, wild), watering treatment (LR, CS, DR) and their interaction did not significantly affect date of emergence across years (Table 2.3.3). However, emergence dynamics varied significantly with the interaction of year and biotype (Table 2.3.3); wild plants emerged later than hybrid plants in 2012 but not 2013 (Figure 2.3.3). Also, fewer wild plants emerged in the first three weeks after tilling than hybrid plants in 2012 but not in 2013 (Figure 2.3.3).

\subsubsection{How will Seedbanks Persist for each Genotype and each Watering Treatment?}

My model of sandbank persistence showed belowground survival for 7.13 years, until depletion, averaged across all 15 populations (standard deviation: 2.50 , range: $4-11$ ). No significant effects were observed for biotype, watering treatment, or their interaction. 
Table 2.3.1: MANOVA of the effects of biotype (wild or crop-wild hybrid) and watering treatment (low rain, control shelter, double rain) on trait (germination, dormancy and mortality) over three removal dates (Spring 2013, Fall 2013, Spring 2014) of radish seeds in King City, ON. Significant F-values $(\mathrm{P} \leq 0.05)$ are in bold. Numerator, denominator degrees of freedom are in subscripts. Seed status was estimated using a tetrazolium stain, as described in the text. Block was excluded as a main effect when it was not a significant factor in the model. Seeds from the CU treatment were excluded from watering treatment due to low sample size.

\begin{tabular}{|l|c|c|c|}
\hline Source of Variation & Spring 2013 & Fall 2013 & Spring 2014 \\
\hline Between Subject Effects & $0.427_{1,7}$ & $0.841_{1,7}$ & $0.070_{1,7}$ \\
\hline Biotype & $1.562_{2,7}$ & $1.583_{2,7}$ & $0.122_{2,7}$ \\
\hline Watering Treatment & $1.439_{2,7}$ & $0.210_{2,7}$ & $0.517_{2,7}$ \\
\hline Biotype x Watering Treatment & & & \\
\hline Multivariate Effects & $\mathbf{5 . 2 8 0}_{2,6}$ & $\mathbf{1 6 . 1 9 6}_{2,6}$ & $\mathbf{1 1 . 9 0 9}_{2,6}$ \\
\hline Trait & & & $1.466_{2,6}$ \\
\hline Trait x Biotype & $\mathbf{7 . 7 3 2}_{2,6}$ & $0.351_{2,6}$ & \\
\hline Trait x Watering Treatment & $1.068_{4,14}$ & $1.759_{4,14}$ & $1.154_{4,14}$ \\
\hline Trait x Biotype x Watering Treatment & $0.174_{4,14}$ & $1.296_{4,14}$ & $0.873_{4,14}$ \\
\hline
\end{tabular}


Table 2.3.2: Average germination, dormancy and mortality rates transformed (see Section 2.3.8), across biotypes (wild, hybrid) of Raphanus seeds, watering treatments [control shelter (CS), double rain (DR), low rain (LR)] and removal dates (Spring 2013, Fall 2013, Spring 2014) in King City, ON. Seed status was estimated using a tetrazolium stain, as described in the text. Control unsheltered treatment excluded from watering treatment due to low sample size. Standard errors are in parentheses. 
Table 2.3.2:

\begin{tabular}{|c|c|c|c|c|c|}
\hline Biotype & $\begin{array}{l}\text { Watering } \\
\text { Treatment }\end{array}$ & $\begin{array}{c}\text { Removal } \\
\text { date }\end{array}$ & Germination & Dormancy & Mortality \\
\hline \multirow[t]{9}{*}{ Hybrid } & \multirow[t]{3}{*}{ LR } & Spring 2013 & $0.68(0.01)$ & $0.41(0.06)$ & $0.78(0.04)$ \\
\hline & & Fall 2013 & $0.51(0.07)$ & $0.53(0.15)$ & $0.82(0.07)$ \\
\hline & & Spring2014 & $0.55(0.06)$ & $0.32(0.06)$ & $0.95(0.02)$ \\
\hline & \multirow[t]{3}{*}{$\mathrm{CS}$} & Spring 2013 & $0.69(0.02)$ & $0.55(0.14)$ & $0.63(0.11)$ \\
\hline & & Fall 2013 & $0.37(0.02)$ & $0.60(0.08)$ & $0.88(0.09)$ \\
\hline & & Spring2014 & $0.62(0.05)$ & $0.46(0.15)$ & $0.78(0.07)$ \\
\hline & \multirow[t]{3}{*}{ DR } & Spring 2013 & $0.62(0.11)$ & $0.44(0.07)$ & $0.80(0.09)$ \\
\hline & & Fall 2013 & $0.63(0.06)$ & $0.49(0.07)$ & $0.76(0.05)$ \\
\hline & & Spring2014 & $0.90(0.08)$ & $0.38(0.06)$ & $0.56(0.05)$ \\
\hline \multirow[t]{9}{*}{ Wild } & \multirow[t]{3}{*}{ LR } & Spring 2013 & $0.71(0.14)$ & $0.51(0.09)$ & $0.65(0.06)$ \\
\hline & & Fall 2013 & $0.48(0.01)$ & $0.69(0.01)$ & $0.71(0.003)$ \\
\hline & & Spring2014 & $0.55(0.11)$ & $0.51(0.06)$ & $0.81(0.05)$ \\
\hline & \multirow[t]{3}{*}{$\mathrm{CS}$} & Spring 2013 & $0.38(0.01)$ & $0.64(0.07)$ & $0.84(0.07)$ \\
\hline & & Fall 2013 & $0.56(0.10)$ & $0.50(0.08)$ & $0.81(0.09)$ \\
\hline & & Spring2014 & $0.58(0.16)$ & $0.45(0.08)$ & $0.81(0.11)$ \\
\hline & \multirow[t]{3}{*}{ DR } & Spring 2013 & $0.36(0.06)$ & $0.52(0.10)$ & $0.95(0.10)$ \\
\hline & & Fall 2013 & $0.56(0.07)$ & $0.55(0.08)$ & $0.77(0.002)$ \\
\hline & & Spring 2014 & $0.66(0.07)$ & $0.43(0.10)$ & $0.75(0.14)$ \\
\hline
\end{tabular}


Table 2.3.3: Repeated measures ANOVA of the effects of biotype (wild or crop-wild hybrid) and watering treatment (low rain, control shelter, double rain) on Raphanus seedling emergence timing (days to emergence, and proportion of the population that emerged within the first three weeks after tilling), during 2012 and 2013 in King City, ON. Significant F-values $(\mathrm{P} \leq 0.05)$ are in bold. Numerator, denominator degrees of freedom are in subscripts. Seeds from the CU treatment excluded from watering treatment due to low sample size. Sphericity was assumed for tests of within-subject effects.

\begin{tabular}{|l|c|c|}
\hline Source of Variation & $\begin{array}{c}\text { Average Date of } \\
\text { Emergence }\end{array}$ & $\begin{array}{c}\text { Proportion Emerged } \\
\text { in First 3 Weeks }\end{array}$ \\
\hline Between Subject Effects & $2.67_{1,12}$ & $1.00_{1,12}$ \\
\hline Biotype & $0.85_{3,12}$ & $1.22_{3,12}$ \\
\hline Watering Treatment & $0.41_{3,12}$ & $0.13_{3,12}$ \\
\hline Biotype x Watering Treatment & $\mathbf{6 . 7 4}_{2,12}$ & $1.46_{2,12}$ \\
\hline Block & \multicolumn{3}{|c|}{} \\
\hline Within Subject Effects & $\mathbf{3 0 . 3 5}_{1,12}$ & $\mathbf{8 5 . 7 1}_{1,12}$ \\
\hline Year & $\mathbf{6 . 1 2}_{1,12}$ & $\mathbf{5 . 1 9}_{1,12}$ \\
\hline Year x Biotype & $0.48_{3,12}$ & $0.23_{3,12}$ \\
\hline Year x Watering Treatment & $0.55_{3,12}$ & $0.23_{3,12}$ \\
\hline Year x Biotype x Watering Treatment & $\mathbf{5 . 3 9}_{2,12}$ & $3.04_{2,12}$ \\
\hline Year x Block & & \\
\hline
\end{tabular}


Table 2.3.4: ANOVAs with biotype (wild and crop-wild hybrid) and watering treatment (low rain, control shelter, double rain) as main effects for average date of emergence and proportion emerged in first three weeks after tilling during 2012 and 2013 in King City, ON. Significant F-values $(\mathrm{P} \leq 0.05)$ are in bold. Numerator, denominator degrees of freedom are in subscripts. Block was excluded as a main effect from model when not significant, as indicated with a dash.

\begin{tabular}{|l|c|c|}
\hline Source of Variation & \multicolumn{1}{|c|}{$\begin{array}{c}\text { Average Date of } \\
\text { Emergence }\end{array}$} & $\begin{array}{c}\text { Proportion Emerged in } \\
\text { First 3 Weeks }\end{array}$ \\
\hline $\mathbf{2 0 1 2}$ & $\mathbf{5 . 4 7}_{1,12}$ & $3.00_{1,14}$ \\
\hline Biotype & $0.59_{3,12}$ & $0.86_{3,14}$ \\
\hline Watering Treatment & $0.39_{3,12}$ & $0.03_{3,14}$ \\
\hline Biotype x Watering & \multicolumn{2}{|c|}{} \\
Treatment & $\mathbf{7 . 3 8}_{2,12}$ & - \\
\hline Block & \multicolumn{3}{|c|}{} \\
\hline 2013 & $0.94_{1,16}$ & $1.22_{1,14}$ \\
\hline Biotype & $1.37_{3,16}$ & $2.11_{3,14}$ \\
\hline Watering Treatment & $0.64_{3,16}$ & $0.62_{3,14}$ \\
\hline Biotype x Watering & & - \\
Treatment & - & \\
\hline Block & & \\
\hline
\end{tabular}


Table 2.3.5: Average days to emergence from tilling (ln transformed) and proportion emerged within first three weeks from tilling (arcsine transformed) across biotypes (wild and crop-wild hybrid) of Raphanus seeds, and watering treatments [control shelter (CS), double rain (DR), low rain (LR)], during 2012 and 2013, in King City, ON. Standard errors are in parentheses.

\begin{tabular}{|c|c|c|c|c|}
\hline Biotype & $\begin{array}{c}\text { Watering } \\
\text { Treatment }\end{array}$ & Year & $\begin{array}{c}\text { Days to } \\
\text { Emergence }\end{array}$ & $\begin{array}{c}\text { Proportion } \\
\text { Emerged in } \\
\text { First } 3 \text { Weeks }\end{array}$ \\
\hline \multirow[t]{8}{*}{ Hybrid } & \multirow[t]{2}{*}{ LR } & 2012 & $3.078(0.143)$ & $0.849(0.221)$ \\
\hline & & 2013 & $2.818(0.008)$ & $1.285(0.010)$ \\
\hline & \multirow[t]{2}{*}{$\mathrm{CU}$} & 2012 & $3.084(0.177)$ & $0.717(0.119)$ \\
\hline & & 2013 & $2.859(0.025)$ & $1.205(0.083)$ \\
\hline & \multirow[t]{2}{*}{$\mathrm{CS}$} & 2012 & $3.173(0.161)$ & $0.513(0.072)$ \\
\hline & & 2013 & $3.040(0.192)$ & $1.045(0.163)$ \\
\hline & \multirow[t]{2}{*}{ DR } & 2012 & $3.019(0.258)$ & $0.581(0.130)$ \\
\hline & & 2013 & $2.852(0.010)$ & $1.198(0.014)$ \\
\hline \multirow[t]{8}{*}{ Wild } & \multirow[t]{2}{*}{ LR } & 2012 & $1.148(1.148)$ & $0.580(0.000)$ \\
\hline & & 2013 & $2.773(0.000)$ & $1.571(0.000)$ \\
\hline & \multirow[t]{2}{*}{$\mathrm{CU}$} & 2012 & $3.247(0.091)$ & $0.474(0.153)$ \\
\hline & & 2013 & $2.869(0.080)$ & $1.172(0.287)$ \\
\hline & \multirow[t]{2}{*}{$\mathrm{CS}$} & 2012 & $3.320(0.282)$ & $0.342(0.236)$ \\
\hline & & 2013 & $2.861(0.042)$ & $1.194(0.103)$ \\
\hline & \multirow[t]{2}{*}{ DR } & 2012 & $3.232(0.113)$ & $0.345(0.183)$ \\
\hline & & 2013 & $2.855(0.039)$ & $1.204(0.097)$ \\
\hline
\end{tabular}




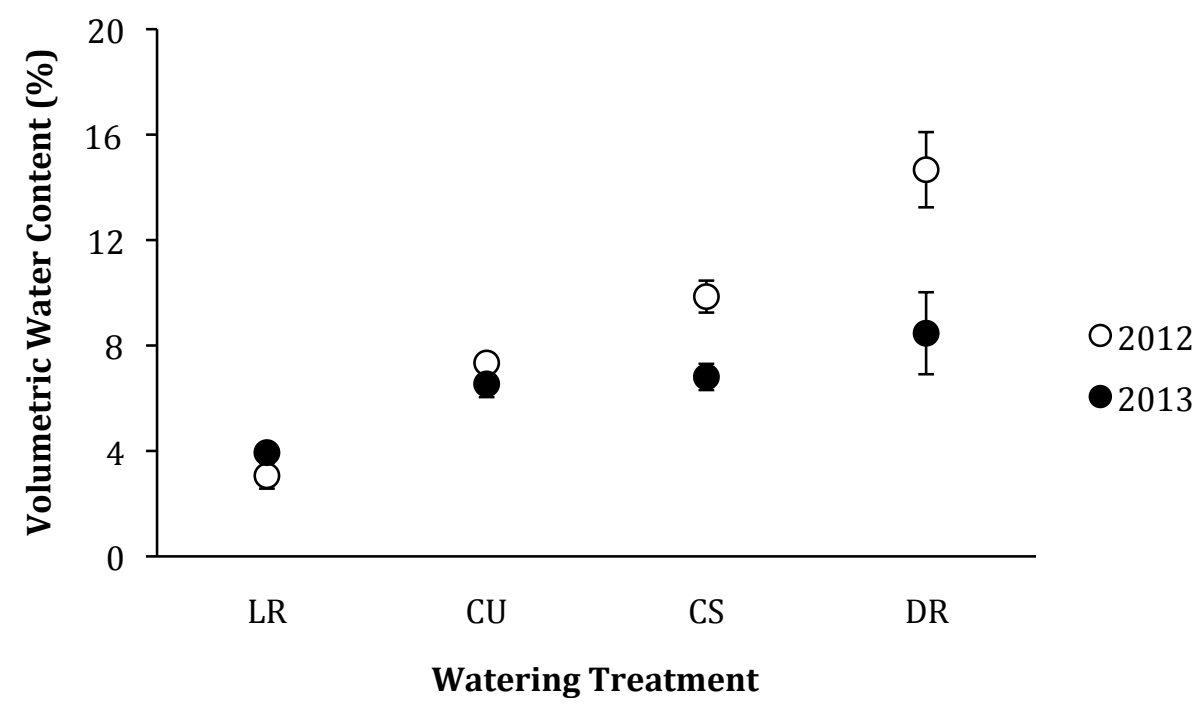

Figure 2.3.1: Percentage volumetric water content among low rain (LR), control unsheltered (CU), control sheltered (CS), and double rain (DR) watering treatments for 2012 and 2013 in King City, ON (+/- SE). Values were obtained by averaging three random readings within a plot. 

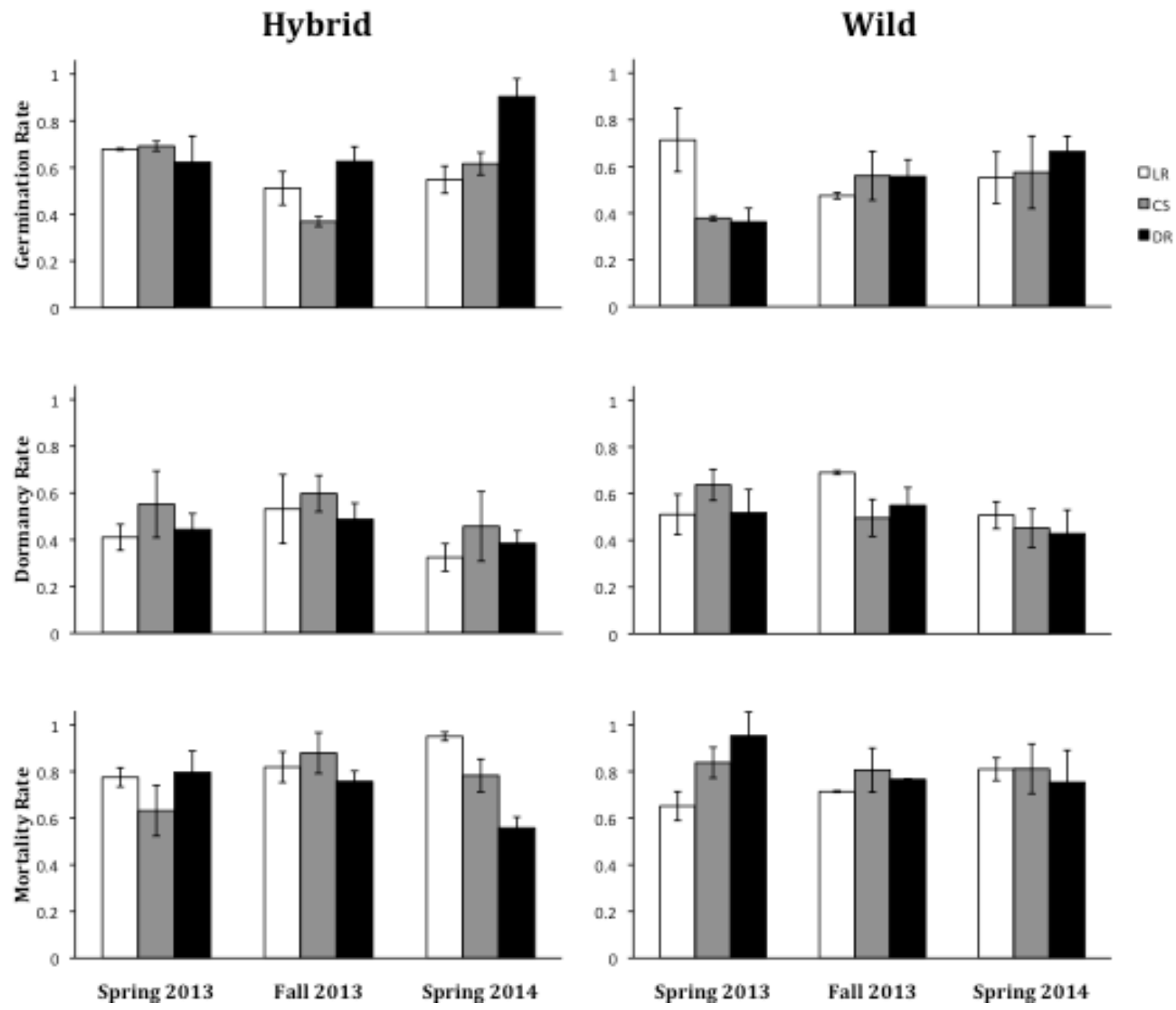

Figure 2.3.2: Average germination, dormancy and mortality rates (arcsine transformed) of seeds removed from soil in Spring 2013, Fall 2013 and Spring 2014, grown under double rain (DR), control shelter (CS), or low rain (LR) watering treatment of wild and crop-wild hybrid Raphanus seeds in King City, ON (+/- SE). Seed status was estimated using a tetrazolium stain. 


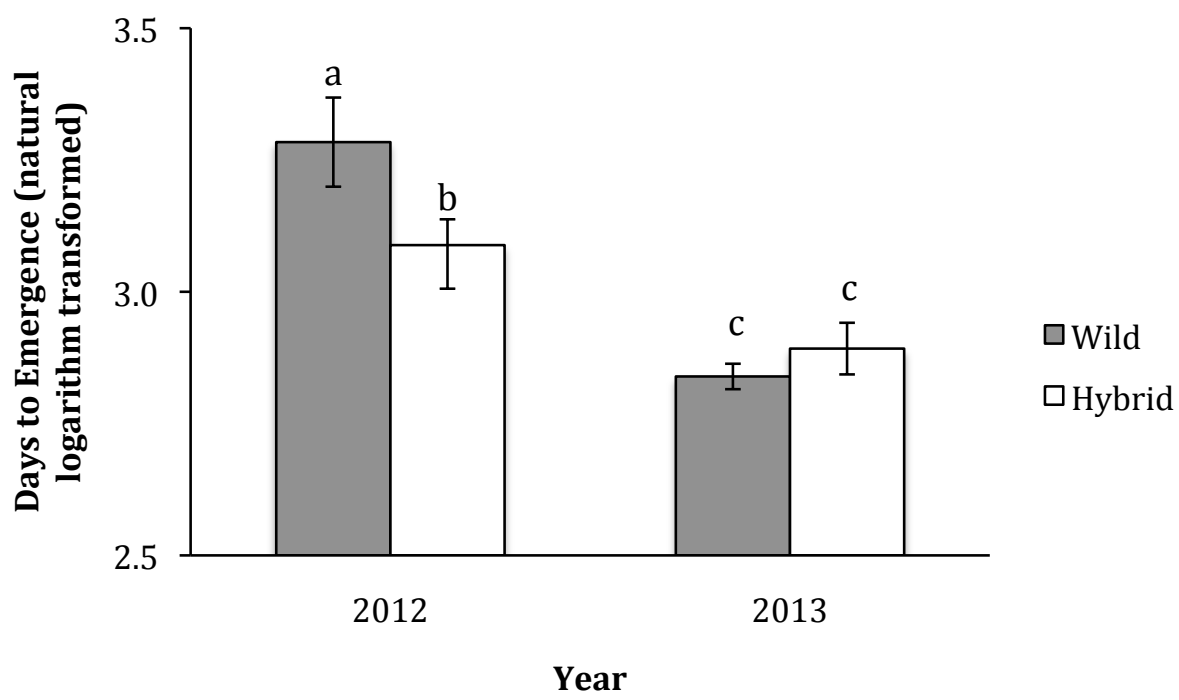

Figure 2.3.3: Average days to emergence after tilling (natural logarithm transformed) across years $(2012,2013)$ and biotypes (wild and crop-wild hybrid) of Raphanus seeds in King City, ON (+/- SE). Significant differences where $\mathrm{P} \leq 0.05$ is indicated by lettering. 


\section{$\underline{2.4 \text { Discussion }}$}

\subsubsection{Summary}

My results suggest the quantity of rainfall received will alter the rates of germination and mortality, depending on the age of the seedbank. Specifically, hybrid seeds germinated more frequently than wild seeds and, in 2013, were less dormant than wild seeds. Further, seeds in drier plots germinated more frequently than other seeds in other watering treatments in Spring 2013 (Figure 2.3.2). Generally, seeds emerged later in 2012 than in 2013, and hybrid seeds emerged earlier than wild seeds in 2012 (Figure 2.3.3).

\subsubsection{Seed Vital Rates}

Seedbank phenology is closely tied to the physical environment due to annual weather cycles altering temperature, light and water availability (Baskin and Baskin 1988; Allen and Meyer 1998). The effect of time since burial and its interaction with soil moisture environment could have affected the ability of Raphanus seeds to respond to favorable or unfavorable environments dynamically over time (Cohen 1966; Sarukhan 1974). For instance, I found germination rates to be highest in the Spring and dormancy rates to be highest in the Fall (Figure 2.3.2), reflecting, perhaps, not only the absolute time since burial, but the sharp differences in environmental conditions among the seasons (Garwood 1983; McLaren and McDonald 2003). Similarly, seed germination in Chenopodium album considerably varied among seasons due to changes in light, water and nutrients (Bouwmeester and Karssen 1993). Germination of seeds could be adapted 
to local, seasonal temperature and precipitation patterns (Baskin and Baskin 1988), and could therefore be predictably high in Spring for the summer annual, Raphanus.

Since I found germination rates changed over time across soil moisture environments, I predict climate change scenarios of punctuated precipitation extremes may have contrasting effects on plant emergence; drought conditions lowering, and high precipitation raising, germination rates gradually over time (IPCC 2012). Seeds that were belowground for the shortest period of time (Spring 2013) showed a marginally significant increase in germination under the 'LR' treatment (Figure 2.3.2) before the implementation of the watering treatment (Eslami et al. 2010). This result suggests that seeds whose maternal environment was stressful may break dormancy early (Wright et al. 1999; Sharif-Zadeh and Murdoch 2000), perhaps to avoid future poor environmental conditions. Water-stressed plants that germinate early tended to exhibit low seed and silique weight suggesting this to be a partly-physical mechanism for seed dormancy in $R$. raphanistrum (Young 2001; Eslami et al. 2006; Eslami et al. 2010). The failure of seeds to germinate after exposure to favorable environmental conditions may be a due to dormancy and could decrease with continued favorable environmental exposure (Koller 1972). Farmers and land managers could benefit if these extremes in precipitation trends remain constant in magnitude and direction. Those dealing with weedy Raphanus spp. may be able to better predict likelihoods that seed banks will be problematic in certain ranges or that they will expand their ranges. Informed land-managers could manipulate water allotment to crop fields under drought or high water conditions, thus managing the mortality and dormancy dynamics of seed banks.

\subsubsection{Emergence Phenology}


All seedling emergence was considerably delayed in 2012 vs. 2013 (Figure 2.3.3). The large phenological difference between years could be due to an experimental duration limitation; the lag time it takes to implement extreme precipitation climate scenarios on plant response naturally occur over a larger time scale than this experiment permitted (Parmesan 2006). If treatments continued, I would expect even earlier emergence in subsequent years, given stronger continuous pressure from an extreme water-rich or water-poor environment. A more likely explanation of the annual variation in emergence patterns could be due to the stark difference in natural precipitation between the two years, with 2013 receiving 117\% more rainfall in May than in 2012, a critical period of emergence. Indeed, within a season, $R$. raphanistrum seeds that break dormancy and emerge earliest have better growth and produce more seeds, than late emergence plants (Cheam 1986). Therefore, earlier emergence is an adaptive trait and hybrid plants possessing the early germination trait inherited from their crop parents may be at an adaptive advantage over wild plants that germinate later (Mercer et al. 2006). However, early germination may be detrimental due to alternative benefits from betweenseason dormancy. This strategy is not only advantageous for avoiding unfavorable environmental conditions, but from fitness benefits for an emerging population that draws seeds not only from the previous years' reproduction, but from several generations before that as well (Templeton 1979). Multigenerational populations are not only boosted in numbers relative to founding generations, but contain a wider range of intra-specific genetic diversity, thus having greater quantity and quality.

I expected wild populations to behave differently than hybrids with respect to seed dormancy and days to emergence (Naylor and Jana 1976). Dormancy is a 
genetically controlled trait in Australian R. raphanistrum and differs in frequency among spatially disparate populations (Cheam 1986; Cheam and Code 1995). In contrast, little is known about the mechanism of dormancy inheritance in my own study system, and future work should determine if hybridization leads to an intermediate level of dormancy, or more complex determination. Wild populations may take longer to emerge than hybrid populations, because cultivated species have been continuously selected for low seed dormancy and high population germination rates that occur simultaneously within a short time window (Koller 1972; Seiler 1992). In contrast, wild species are expected to have delayed germination and a wider range of germination dates (Teo-Sherrell 1996). Earlier emergence is correlated with increased fecundity and greater potential for invasiveness (meta-analysis by Verdu and Traveset 2005). As well, this trend has been found in hybrid relative to wild radish (Hovick et al. 2012). Wild populations' emergence phenology eventually mirrored that of hybrids (Figure 2.3.3), suggesting that targeting weed biotypes may be difficult in mixed populations when both biotypes emerge early and additionally, at the same time. These new emergence phenologies resulting from cropwild hybridization could potentially avoid suppression in human-managed and natural communities. 


\section{CHAPTER 3. MEASURING THE RELATIVE INVASIVENESS OF CROP-WILD HYBRID RAPHANUS LINEAGES ACROSS A PRECIPITATION GRADIENT USING A LIFE TABLE RESPONSE EXPERIMENT}

\section{$\underline{3.1 \text { Introduction }}$}

\subsubsection{Climate Change is Happening}

Human-mediated global climate change, a consequence of accelerated greenhouse gas emissions (Solomon et al. 2009; Moss et al. 2010), is drastically altering global temperatures to new seasonal highs (Stachowicz et al. 2002; Walther et al. 2002; Root et al. 2003; Parmesan 2006; Visser 2008) and long-term precipitation patterns to an extraordinary degree (Barnett et al. 2005; O'Gorman and Schneider 2009); these changes are expected to have dramatic effects on ecological and evolutionary processes worldwide (Dukes and Mooney 1999). Precipitation projections reveal expectations of punctuated and extreme rainfall patterns over terrestrial regions, including greater instances of severe drought and flooding (Christensen and Christensen 2003; Jentsch et al. 2007; IPCC 2012). Shifts in precipitation frequencies and magnitudes will not be spatially consistent; instead, wet regions are expected to get wetter, whereas dry areas are expected to get dryer, and northern latitudes are expected to receive more precipitation than southern latitudes (Dore 2005). As well, the timing and seasonality of extreme precipitation events will increase in variance (Palmer and Ralsanen 2002). Shifting climatic conditions have previously, and will continue to affect plant phenology and fecundity, key traits that affect the relative success of common weeds (Baker 1965; Parmesan 2006; Cleland et al. 2007). 


\subsubsection{Climate Affects Plant Life Histories}

Plant development and phenology are sensitive to seasonal variation in climate. Annual plant fitness relies on individual survival through successive life-history stages and reproduction within the context of environmental cues that inhibit or encourage germination, vegetative growth, pollination and seed development (Marks and Prince 1981; Verdu and Traveset 2005). These transitions are highly sensitive to abiotic variation in the physical environment, particularly precipitation (Petru et al. 2006). Plant productivity and population growth rates vary with precipitation (Lucas et al. 2008; Shafran-Nathan et al. 2013), largely due to moisture sensitivity of specific life-history transition rates such as germination (Freas and Kemp 1983) survival (Gutterman and Evenari 1994; Zhu et al. 2014), flowering time (Franks et al. 2007), and fecundity (Herrera 1991). Changing climatic conditions may have a particularly dramatic effect on agricultural ecosystems, where farmers rely on high rates of germination and survival, and high fecundities in cultivated species while attempting to minimize these same lifehistory traits in weedy competitors.

\subsubsection{Expect Different Life-history Responses to Identical Environmental Cues in Crops and Weeds}

In agricultural plant communities, where crop and compatible weedy relatives coexist (Arias and Rieseberg 1994; Jarvis and Hodgkin 1999; Chen et al. 2004), I may expect different life-history responses to identical environmental cues (Adler et al. 1993). Plant breeders can develop cultivars with high-yielding life histories by selecting for tolerance to water stress (Passioura 2006; Tuberosa and Salvi 2006), and natural selection 
would make wild relatives tolerant as well, though perhaps not in the same direction of selection. Contrasting strategies of resource allocation in high- and low-stress environments may be driven by adaptive physiological and morphological differences between wild and crop plants, respectively (Johnson et al. 2000; Snow et al. 2003). As well, farmers have artificially selected for cultivated strains to be tolerant to environmental pressures (Bradshaw 1984; Bone and Farres 2001). In contrast, I would expect wild plants to contain more phenotypic plasticity for traits like fecundity, so as to adjust their resource allocation for optimal fitness (e.g. greater reproductive than vegetative investment) (Schlichting 1986). If crop plants hybridize with wild relatives, the resulting crop-wild hybrid offspring could exhibit a combination of these alternate life-history strategies, and potentially succeed in environments that exclude or minimize the weediness of the wild parent (Barton and Hewitt 1985; Emms and Arnold 1997; Campbell and Waser 2001; Jarvis et al. 2008).

The weediness of a plant is dictated by multiple interacting components of fitness, which when taken by themselves do not give the net effect of fitness. Below, I explore the demographic consequences of altered moisture in weedy hybrid and non-hybrid populations using a comprehensive life-table response experiment (LTRE) approach. Transitions among key life-history stages (e.g., rates of germination, survival and reproduction) are closely associated with whole plant fitness and collectively contribute to population growth rate ( $\lambda$ ) (Caswell 2001). An LTRE empirically tests the effect of experimental manipulations, such as biotype and precipitation, on a population's growth, using demographic transitions (or vital rates). Vital rates are proportional conversions from one life stage to another that comprise the entire life cycle of a plant, and are 
integral to quantifying experimental effects on overall $\lambda$ (Bergelson 1994; Bullock 1999).

For example, fecundity is expected to strongly contribute to $\lambda$ in annual plants (Campbell et al. 2014). By using matrix-modeling approaches, I can integrate life-cycle data to generate predictions of population growth and invasiveness across a gradient of soil moistures (Parker 2000; Caswell 2001; Koop and Horvitz 2005). Comparative demographic studies of this nature are essential to test whether crop-wild hybridization can lead to greater population growth in new climatic scenarios, whether due to invasion or climatic change in one location.

\subsubsection{Objectives, Questions and Predictions}

As human-mediated global climate change continues to alter precipitation patterns, plant population growth and persistence may be profoundly affected, indirectly via moisture responses of demographic life-history parameters. I assess how water availability influences vital rate transitions of wild (Raphanus raphanistrum) and cropwild hybrid ( $R$. raphanistrum $\mathrm{x}$ R. sativus) populations of wild radish

1. Do altered rainfall patterns affect population growth of weedy populations?

a. Do populations that receive above average rainfall have higher population growth rates $(r$ or $\lambda)$ than populations that receive average and below average rainfall? I predict that populations will gradually respond to increased rainfall with greater $r$ and $\lambda$. 
b. Does the response to altered rainfall patterns depend upon biotype? I expect the population growth of hybrid populations to covary with soil moisture more strongly than that of wild populations.

2. Do hybrid populations have higher population growth rates than wild populations?

a. How does the instantaneous rate of population growth $(r)$ of hybrid populations compare with the $r$ of wild populations? I expect hybrid populations to have higher $r$ than wild populations

b. How does the asymptotic intrinsic growth rate $(\lambda)$ of hybrid biotypes compare with the $\lambda$ of wild populations? I expect hybrid populations to have higher $\lambda$ than wild populations.

3. How do transitions among life-history stages contribute to relative invasiveness across watering treatments and biotypes? Fecundity will contribute the most to relative invasiveness and this will be heightened in stressful environments.

\subsection{Materials and Methods}

\subsubsection{Experimental Approach}

I compared the demography of wild radish (Raphanus raphanistrum) and cropwild hybrid radish ( $R$. raphanistrum $x$ R. sativus) populations across an experimentally manipulated soil moisture gradient (Section 2.3). Field populations of wild crop-wild hybrid radish were established in 2011 and received one of four watering treatments over the 2011, 2012 and 2013 field seasons. Weekly population censuses $(2012,2013)$ assessed the number of seedlings emerging from the soil, their rate of survival and eventual fecundity. From this life-history data, I determined intrinsic $(r)$ and asymptotic 
( $\lambda$ ) population growth rates, contributions, sensitivities and elasticities using matrix algebra.

\subsubsection{Study Species}

I used lines of Raphanus raphanistrum (wild radish or jointed charlock) and cultivated R. sativus (Brassicaceae). Both species are self-incompatible, insect-pollinated, and readily hybridize (Ellstrand and Marshall 1985; Snow et al. 2001). The term 'biotype' is henceforth assigned to describing $R$. raphanistrum, $R$. sativus, and the hybrid genotype created from their crossing. Wild radish is a challenging weed to control, with its longlived seed bank, high genetic variability, and early emergence after soil disturbance (Holm et al. 1997; Warwick and Francis 2005). It has been reported as a weed problem in more than 45 crop species in at least 65 countries (Holm et al. 1997). Plants go through a sequential life cycle subject to mortality at any stage (Figure 3.2.3). During hybridization, reciprocal translocation results in reduced pollen fertility in $F_{1}$ plants (Panetsos and Baker 1967). Petal colour of the R. sativus cultivar I used in this experiment ranges from white to pink/violet, whereas the wild $R$. raphanistrum population used has a background petal colour of yellow or bronze (Conner and Via 1993). In Raphanus, petal colour is determined by simple Mendelian genetics at a single locus, where the white allele is dominant and the yellow allele recessive (Panetsos and Baker 1967; Stanton et al. 1989).

\subsubsection{Study Site}


I conducted this study at two locations between 2010 and 2013. The parental lineages were grown at the Ohio State University's Waterman Farm, Columbus, OH USA $\left(40^{\circ} 0{ }^{\circ} \mathrm{N}, 83^{\circ} 1\right.$ ' $\mathrm{W}, 232 \mathrm{~m}$ asl $)$ in 2010 . Seeds $\left(\mathrm{F}_{1}\right)$ collected from the $\mathrm{F}_{0}$ parental generation were translocated to the Koffler Scientific Reserve (KSR) at Joker's Hill, King City, ON Canada (44 $0^{\circ} \mathrm{N}$; 79³' W, $285 \mathrm{~m}$ asl) for field experiments from 20112013 , involving $F_{1}$ to $F_{3}$ generation offspring. Over the course of this experiment, the growing season was roughly the four month period between the third week of May and the third week of September of each year (see Section 2.3.3 for more information).

\subsubsection{Seed Sources for Replicated Populations}

Wild radish (R. raphanistrum) seeds were collected haphazardly by selecting fruit from 60 yellow-flowered maternal plants across three field populations near Binghamton, NY, USA (Conner et al. 1996). From these seeds, a population of $>200$ plants was grown for several generations in a greenhouse in East Lansing, MI USA (Conner et al. 1996). Seeds of crop-wild hybrids were always collected from wild radish ( $R$.

raphanistrum) maternal plants with pollen contributed from cultivated radish (R. sativus), 'Red Silk' plants (Harris-Moran Seed Co., Modesto, CA, USA), a common variety. From these sources, wild and cultivated radish parental populations $\left(\mathrm{F}_{0}\right)$ were germinated and grown to the seedling stage in a greenhouse at Ohio State University, Columbus, $\mathrm{OH}$ USA in May 2010.

During the summer of 2010, 36 populations of nine cultivated and nine wild seedlings were transplanted from the greenhouse to the Waterman Farm (for description, see Section 3.2.2) into field plots. Seedlings were transplanted into one of four watering 
treatment plots (see Section 3.2.5 for a complete description of watering treatments) in a complete randomized block design with one plot per treatment per block, making nine blocks. Plots were separated by at least $200 \mathrm{~m}$ to reduce pollen movement. In addition to wild and cultivated radish, each plot also contained nine Helianthus annuus and nine Helianthus petiolaris plants in a clustered design (see Sneck 2012, unpub.). Seedlings of each species were planted in three rows of three plants each, with approximately $30 \mathrm{~cm}$ of spacing between plants. Natural cross-pollination allowed for the mating between $R$. raphinistrum and $R$. sativus to create the crop-wild hybrid biotype. Crop-wild hybrid seeds were collected only from wild radish mothers for experimental use as the $\mathrm{F}_{1}$ generation in 2011 .

\subsubsection{Establishment of Replicated Populations}

In 2011, I established 24 plots (from the original 40 due to practicality) of wild and $F_{1}$ crop-wild hybrid radish in the field at KSR (for description, see Section 3.2.2) from $\mathrm{F}_{0}$ plants grown at the Waterman Farm. All plots were a minimum distance of $40 \mathrm{~m}$ from each other to prevent pollen movement among plots. Due to the considerable variation in physical characteristics (i.e. elevation, slope, soil quality, proximity to tree cover) among plot sites, I used a complete randomized block design of three blocks, each containing one plot per treatment per biotype per block. On average, plots within a block were closer together than plots between blocks, with a couple of exceptions (Plots 1-9; 16-17). Plots were $2.44 \mathrm{~m}$ by $3.05 \mathrm{~m}$ in area, marked by four corner posts. In preparation of planting, each plot was tilled and weeded beginning in the second week of May each year. 
Seeds of the $F_{1}$ generation were germinated and grown to seedlings in a greenhouse at KSR before being transplanted to the field. In each plot, 117 randomly selected seedlings were planted approximately $15 \mathrm{~cm}$ apart. When plants flowered, petal colour was noted; $F_{1}$ plants with yellow petal colour were recorded as wild biotype, and $\mathrm{F}_{1}$ plants with white petal colour were recorded as hybrid biotype. Within a block, plots were randomly assigned to a biotype treatment; any plant representing the "wrong" biotype relative to the assigned biotype of the plot was removed upon the emergence of petals. Flowering plants were allowed to fruit and senesce naturally until their seeds fell to the ground, which became the $\mathrm{F}_{2}$ generation in 2012 (and possibly 2013 if seeds remained dormant below-ground). In this same way, seeds from naturally falling $F_{2}$ fruit became the $\mathrm{F}_{3}$ generation in 2013 (containing both offspring from $\mathrm{F}_{2}$ seeds and dormant $F_{1}$ seeds). Seeds from a small proportion of plants in Fall 2012 and 2013 were harvested to assess individual fecundity, otherwise, seed dispersal occurred naturally.

\subsubsection{Experimental Treatments}

Trays of seeds were assigned to plots in one of four experimental watering treatments: Control Unsheltered (CU), Low rain (NR), Control Shelter (CS), or Double Rain (DR) (for details on watering treatments seeds were subject to during the 2013 growing season, see Section 2.2.6; for image see Figure 2.2.1).

\subsubsection{Annual Surveys of Replicated Populations}

To determine differences in intrinsic population growth rates $(r)$ due to biotype and/or watering treatment, yearly counts were conducted in 2012 and 2013. Using the 
number of individuals counted within the entire plot in 2011 and within the sub-plots in 2012 and 2013, I calculated the density (number of individuals $/ \mathrm{cm}^{2}$ ) to determine how growth rates changed year to year. The annual population growth rate $(r)$ was calculated as the difference in natural log transformed population size density $(N)$ for year $_{t}$ and year ${ }_{t-}$ 1. I ran a mixed-model ANOVA to determine whether biotype, watering treatment, or their interaction resulted in significant changes in $r$.

\subsubsection{Weekly Surveys of Replicated Populations}

As a quantitative proxy to the watering treatments, I measured the volumetric water content in the soil (see Chapter 2 for details).

Each year, within 16 days of tilling, I established $1 \mathrm{~m} \mathrm{x} 1 \mathrm{~m}$ subplots, centrally located within each plot. I intended to follow approximately 50 plants per subplot, but plant density varied within subplots. When more than 50 plants germinated within a subplot, I reduced the size of the subplot by consistently reducing the subplot on one side until it had approximately 50 plants again.

Between May 24 - October 17, 2012 and June 6 - October 25, 2013, I followed individual plants within a subplot with small, numbered flags (for tracking individual plants) added within a week of emergence (at the weekly census). Once emerged, plants were classified into one of nine life-history stages or designations that were eventually condensed into four stages (see Figure 3.2.3):

1. Cotyledonous - emerged individual that hasn't developed true leaves yet;

2. Seedlings - young individual with one or two true leaves;

3. Rosette - plant with more than two true leaves; 
4. Bolting - plant with elongating floral meristem;

5. Flowering - plant with at least one open flower;

6. Fruiting - plant with at least one fruit;

7. Harvested - senesced plant that was harvested by experimental researchers;

8. Missing - plant could not be found at one or more weekly censuses but was eventually relocated;

9. Dead - plant died or went missing and was never found.

The original nine stages were selected by experienced researchers based on information commonly reported in the literature and my own research experience (Cheam and Code 1995; Campbell et al. 2014). Four life stages were removed to simplify my analyses without drastically changing the final results and to conform with parameters most commonly reported in the literature. A sub-sample of approximately 30 seeds/plant from 2012 harvested plants was used in the seed-burial experiment for viability testing (see section 2.2). This number was chosen to balance having adequate statistical significance, and not having to exclude excessive numbers of plants and/or plots with too few seeds.

Plants with fruit were harvested as they senesced (when most fruit were mature and were beginning to fall from the plant) and at the last weekly census of the growing season, when there were no new fruit development on any plants (Z. Teitel, pers. obs.), regardless of plant maturity. Plants that did not produce fruit were harvested at the last census of the growing season. Above-ground plant material was stored in paper bags and dried in an oven for at least 7 days at $30^{\circ} \mathrm{C}$. For 30 randomly selected, reproductive plants 
per plot (or all plants when there were fewer than 30 plants that reproduced in the demography plot), I counted the number of fruit per plant. Number of seeds per fruit was assessed by counting locules in a silique for 10 randomly chosen fruits per plant. To estimate the number of seeds per plant, I multiplied the average number of seeds per fruit by the number of fruits.

\subsubsection{Analysis of Plot Characteristics and $\lambda$}

To simplify my analysis, each matrix contained data at the annual level about a population's demography (i.e., 2012 and 2013). My weekly censuses monitored nine lifehistory stages or designations (see Section 3.2.8) but were amalgamated into four key life-history stages of seed, cotyledon, non-flowering adult and flowering adult that explain five vital rates of seed germination, seed dormancy, survival to non-flowering

adult, survival to flowering adult and fecundity (Campbell et al. 2014). To accommodate this synthesis, seedlings were scored as cotyledons; bolted plants were scored as nonflowering adults; and fruiting and harvested plants were scored as flowering adults. Seed dormancy values were estimated by incorporating results from seed burial experiment (see Chapter 2), such that dormancy vital rate cells were weighted by dormancy rates of their corresponding plot and removal date, adjusted for population size. Mortality could occur at each stage except for fecundity and is reflected in the proportion of individuals that survive to the next life-history stage. A plant that went missing for more than two weeks was presumed dead, though occasionally missing plants would be found in subsequent weekly censuses. If, upon rediscovery, the plant either did or did not mature 
from the last known entry, I filled in the missing week(s) with that last known census entry.

Vital rate data were summarized into matrices for individual plots, such that each plot of a particular factorial combination served as an individual replicate. In total, 48 matrices were constructed from my 2012 and 2013 data. Matrix modeling and analyses were performed using MATLAB (v.2012a; The Mathworks, Inc., Natick, Massachusetts, U.S.A). From this, I calculated: Dominant eigenvalues or asymptotic population growth rates $(\lambda)$ for a given matrix $\mathrm{A}$; sensitivities, being the absolute change in lambda resulting from a change in the vital rate, $s_{i j}=\frac{\partial \lambda}{\partial a_{i j}}$, where $a_{i j}$ are elements in matrix A; elasticities, how lambda proportionally changes with changes to vital rates, $e_{i j}=\frac{a_{i j}}{\lambda} \frac{\partial \lambda}{\partial a_{i j}}$; and contributions to $\Delta \lambda$, calculated by weighting the differences in vital rates by their sensitivities, $\Delta \lambda \approx \sum_{i j} \frac{\partial \lambda}{\partial a_{i j}} \Delta a_{i j}$, where $\Delta a_{i j}$ is the change in $a_{i j}$ between hybrids and wilds.

To determine how genotype and environment determine $\lambda$, I conducted a Type III ANOVA in which biotype, watering treatment, block, and their interaction were fixed effects for the response variable of $\lambda$. When performing a life table response experiment (LTRE), the vital rates of an organism's life history are used as the response variable to experimental treatments (Caswell 2001). I determined which vital rates have the greatest contributing effect on population growth rates using elasticity and sensitivity analyses.

Sensitivities were calculated as the absolute change in $\lambda$ resulting from a change in a given vital rate. Elasticities, which describe how $\lambda$ proportionally changes with changes in vital rate (Brault and Caswell 1993; Benton and Grant 1999), were calculated 
for every individual vital rate and treatment combination by dividing each non-zero matrix entry by its dominant eigenvalue and weighting it by its sensitivity. Finally, the contributions of a given vital rate to population-level differences between biotypes were calculated by weighting the differences in vital rates by their sensitivities. I estimated the total difference in $\lambda$ between the average and a given treatment combination by adding up all of the vital rate contributions together (Caswell 2001). Because contribution parameters describe the effects of one matrix relative to another, I assigned a reference matrix for comparison, which was consistently the wild matrix relative to the corresponding hybrid matrix (Caswell 2001). All parametric tests were done using SPSS Statistics 21 (1989, 2012; SPSS Inc., Chicago Ilinois USA). 


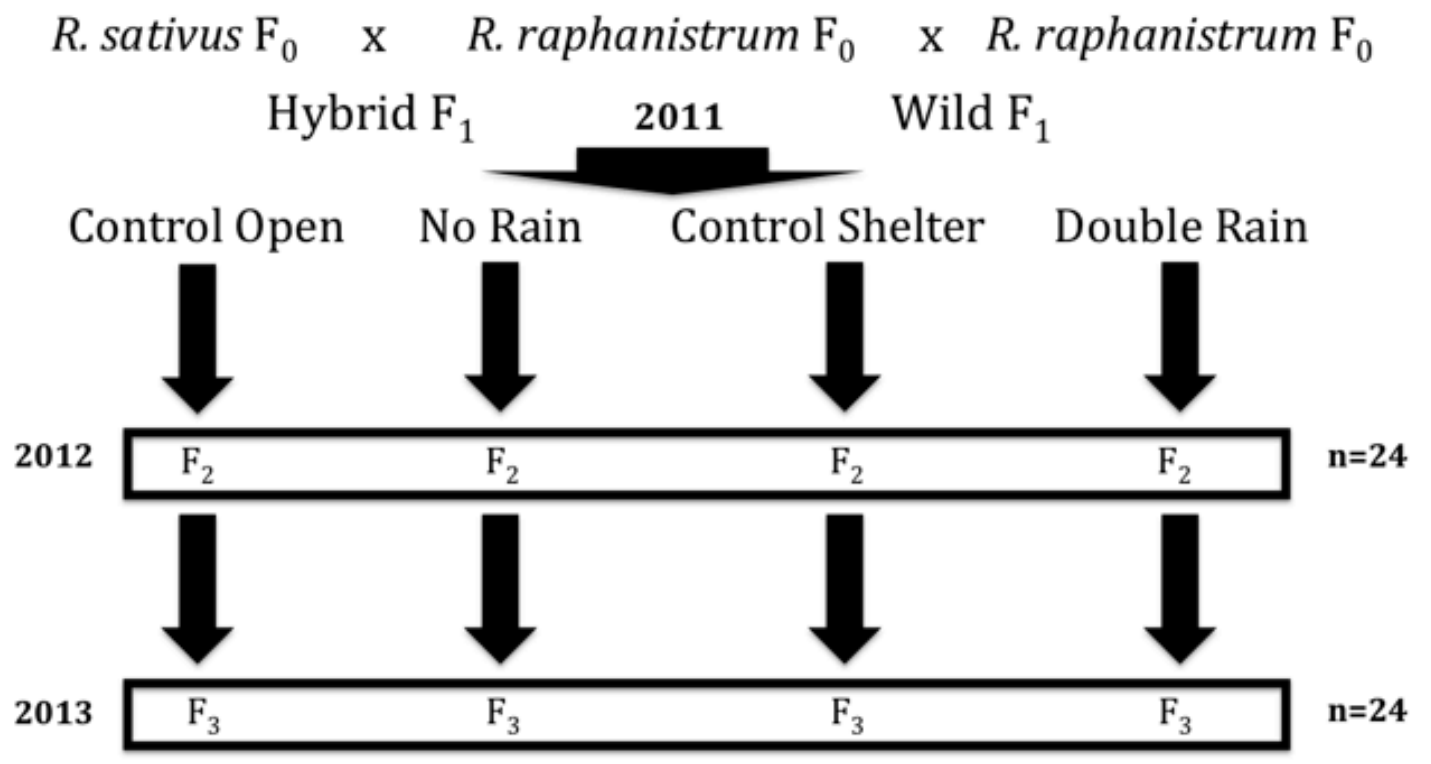

Figure 3.2.1: Schematic of experimental design showing biotype and treatment assignments over year and generation for 24 plots. 


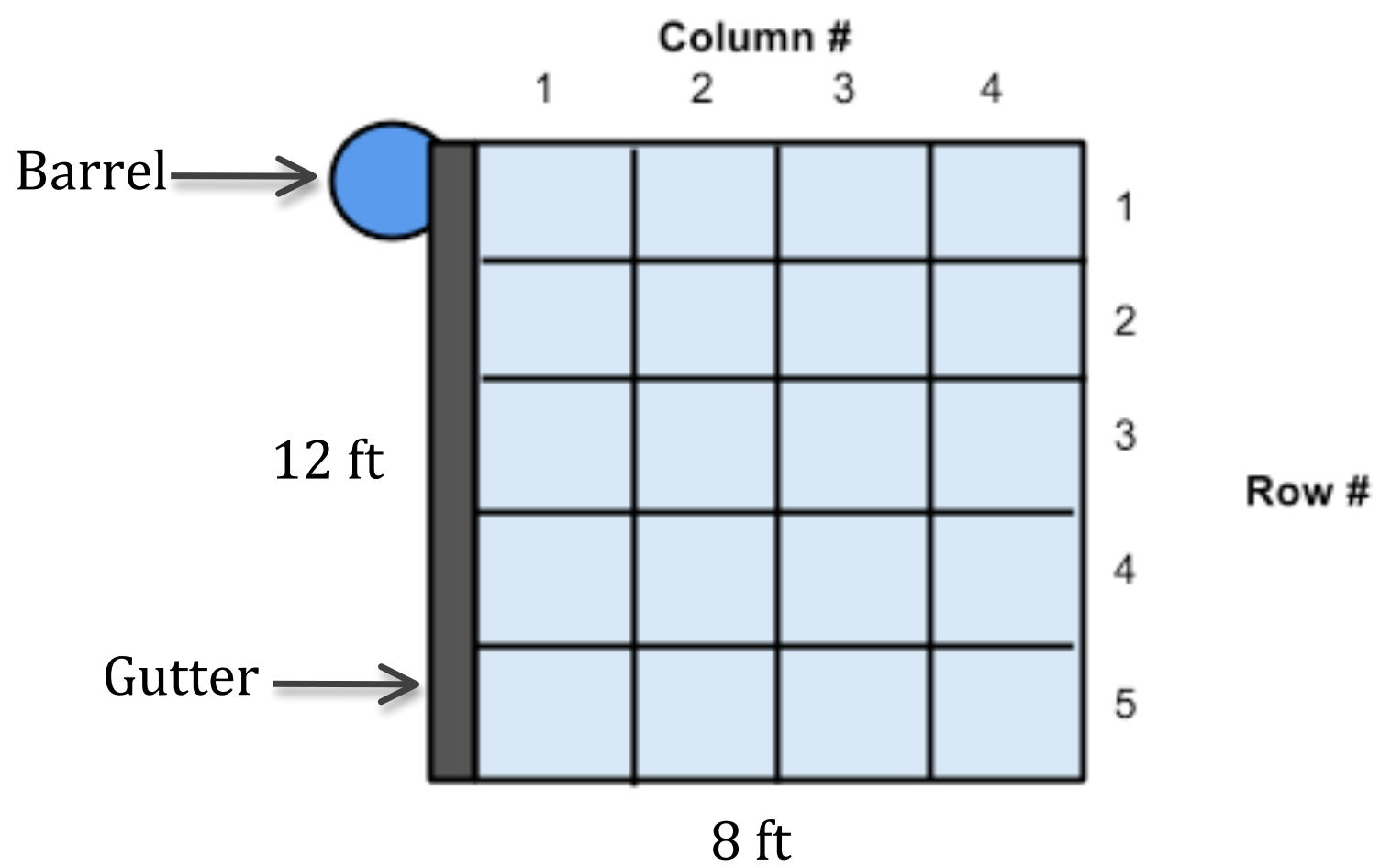

Figure 3.2.2: Layout of precipitation shelter over plot. Key materials, dimensions, and sub-sampling quadrants for flower counting are given. 


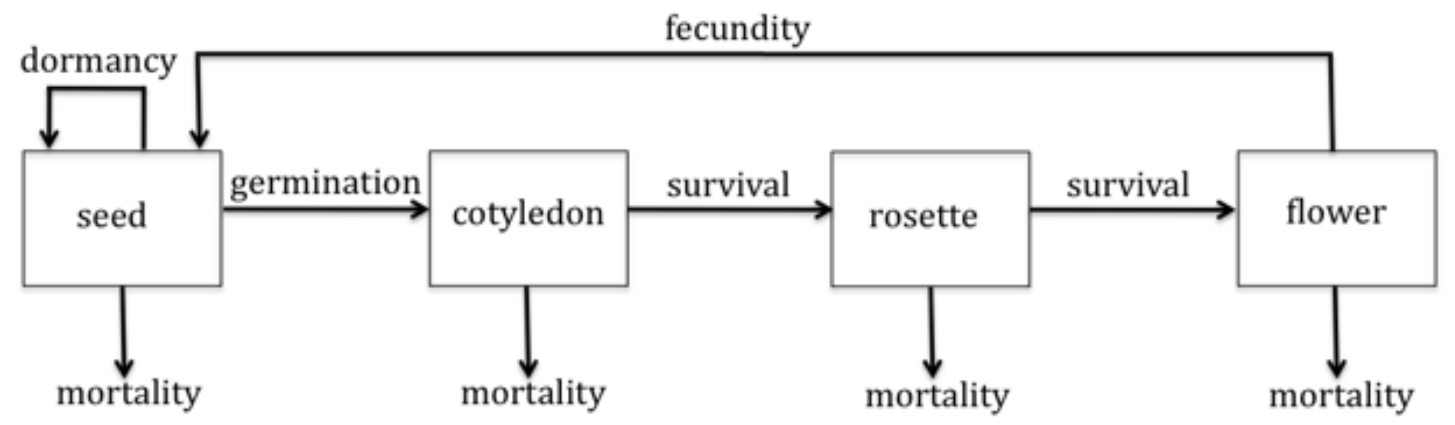

Figure 3.2.3: Raphanus life cycle represented in matrices. Broken up into four life stages of seed, cotyledon, non-flowering adult and flowering adult; five vital rates of dormancy, germination, survival to rosette, survival to flowering; mortality can occur at any stage. 


\subsection{Results}

\subsubsection{Effect of Precipitation}

Across two generations, soil moisture did not significantly affect instantaneous population growth rates $(r)\left(\mathrm{F}_{3,14}=1.52, \mathrm{P}=0.25\right)$. However, in the first generation, $\mathrm{LR}$ populations grew slower than populations experiencing other soil moisture treatments $\left(\mathrm{F}_{3,14}=6.35, \mathrm{P}=0.0061 ; \mathrm{X}_{\mathrm{LR}}=0.3731, \mathrm{X}_{\mathrm{CU}}=2.8956, \mathrm{X}_{\mathrm{CS}}=3.0633, \mathrm{X}_{\mathrm{DR}}=3.9647\right)$. In contrast, in the second generation, LR populations exhibited significantly higher instantaneous population growth rates than populations grown in other soil moisture treatments $\left(\mathrm{F}_{3,14}=3.38, \mathrm{P}=0.048 ; \mathrm{X}_{\mathrm{LR}}=2.0522, \mathrm{X}_{\mathrm{CU}}=-0.4936, \mathrm{X}_{\mathrm{CS}}=0.4472, \mathrm{X}_{\mathrm{DR}}=0.04061\right)$. Lastly, $\mathrm{I}$ saw no significant genotype by environment interaction across both generations $\left(\mathrm{F}_{3,14}=1.25, \mathrm{P}=0.33\right)$, or in the second generation $\left(\mathrm{F}_{3,14}=1.37, \mathrm{p}=0.29\right)$. However, in the first generation wild populations grown in LR conditions had a significantly slower $r$ than any other genotype by environment combination $\left(\mathrm{F}_{3,14}=3.94, \mathrm{P}=0.031\right)$. Neither watering treatment $\left(\mathrm{F}_{2,9}=0.634, \mathrm{P}=0.553\right)$, nor its interaction with biotype $\left(\mathrm{F}_{2,9}=1.414, \mathrm{P}=0.292\right)$ had a significant effect on population growth rate measured as lambda $(\lambda)$, across years (2012, 2013) (Table 3.3.1). Block was not a significant effect in the model and was, therefore, removed.

\subsubsection{Effect of Biotype}

From $\mathrm{F}_{1}$ to $\mathrm{F}_{3}$, hybrid populations had higher instantaneous population growth rates than wild populations $\left(\mathrm{F}_{1,14}=37.18, \mathrm{P}<0.0001\right)$. In the first generation of population growth $\left(\mathrm{F}_{1}-\mathrm{F}_{2}\right)$, hybrid populations grew four times faster than wild populations $\left(F_{1,14}=29.43, P<0.0001 ; X_{\text {hybrid }}=4.23, X_{\text {wild }}=0.92\right)$. In the following generation, I saw no 
significant difference in population growth between biotypes $\left(\mathrm{F}_{1,14}=1.17, \mathrm{P}=0.30\right)$. Hybrid populations had marginally significantly higher asymptotic population growth rates, when measured as $\lambda$, across years (Figure 3.3.1, Table 3.3.1). Block was not a significant effect in the model and was, therefore, removed.

\subsubsection{Vital Rates}

Life-history transitions contributed to changes between hybrid and wild average population growth rates to different degrees and directions (Figure 3.3.2). In general, fecundity contributed to differences in $\lambda$ to the greatest degree, followed by germination, then survival to flowering and finally survival to rosette and dormancy (Figure 3.3.2). Differences in germination and survival-to-rosette between hybrid and wild populations led to higher relative population growth rates in hybrid vs. wild populations (Figure 3.3.2). In contrast, differences in dormancy and survival-to-flowering led to higher relative population growth rates in wild versus hybrid populations (Figure 3.3.2). However, fecundity only contributed positively to hybrid $\lambda$ relative to wild $\lambda$ when precipitation was altered and not under the CS treatment (Figure 3.3.2). 
Table 3.3.1: Repeated measures ANOVA with year $(2012,2013)$ as within subject effect; biotype (wild and crop-wild hybrid), and watering treatment (low rain, control shelter, double rain) as between subject effects for asymptotic population growth rate $(\lambda)$ of Raphanus grown in King City, ON. Values are F-statistics d.f., d.f. total. $\mathrm{P}<0.1,{ }^{*} \mathrm{P}<0.05$, ** $\mathrm{P}<0.01,{ }^{* * *} \mathrm{P}<0.001$. Block was excluded as main effect from model because of lack of significance. Control unsheltered treatment excluded from watering treatment due to low sample size. Sphericity was assumed for tests of within-subject effects.

\begin{tabular}{|l|c|}
\hline Source of Variation & $\begin{array}{c}\text { Asymptotic Population } \\
\text { Growth Rate }(\lambda)\end{array}$ \\
\hline Between Subject Effects & $3.429_{1,9}{ }^{+}$ \\
Biotype & $.634_{2,9}$ \\
Watering Treatment & $1.414_{2,9}$ \\
\hline Biotype x Watering Treatment & \\
\hline Within Subject Effects & $2.987_{1,9}$ \\
\hline Year & $.2832_{2,9}$ \\
Year x Biotype & $.589_{2,9}$ \\
Year x Watering Treatment & $2.426_{2,9}$ \\
Year x Biotype x Watering Treatment & \\
\hline
\end{tabular}


Table 3.3.2: Two general linear model, univariate ANOVAs with biotype (wild, cropwild hybrid) and watering treatment (low rain, control shelter, double rain) as main effects for asymptotic population growth rate $(\lambda)$ during 2012 and 2013 for Raphanus populations grown in King City, ON. Values are $\mathrm{F}_{\text {-statistics }}$ d.f., d.f. total. $+\mathrm{P}<0.1, * \mathrm{P}<0.05$, ** $\mathrm{P}<0.01, * * * \mathrm{P}<0.001$. Block was excluded as main effect from model because of lack of significance. Control unsheltered treatment excluded from watering treatment due to low sample size.

\begin{tabular}{|l|c|}
\hline Source of Variation & $\begin{array}{c}\text { Asymptotic Population } \\
\text { Growth Rate }(\lambda)\end{array}$ \\
\hline $\mathbf{2 0 1 2}$ & $3.087_{1,9}$ \\
Wiotype & $0.884_{2,9}$ \\
Biotype x Watering Treatment & $2.685_{2,9}$ \\
\hline $\mathbf{2 0 1 3}$ & \\
\hline Biotype & $1.615_{1,9}$ \\
Watering Treatment & $0.309_{2,9}$ \\
Biotype x Watering Treatment & $0.638_{2,9}$ \\
\hline
\end{tabular}


Table 3.3.3: Average population growth rate $(\lambda)$ across biotypes [wild (W), crop-wild hybrid $(\mathrm{H})$ ], watering treatments [control shelter (CS), double rain (DR), low rain (LR)] and years $(2012,2013)$ for Raphanus populations grown in King City, ON. Standard errors are in parentheses. Control unsheltered treatment excluded from watering treatment due to low sample size.

\begin{tabular}{|c|c|c|c|}
\hline Year & $\begin{array}{l}\text { Watering } \\
\text { Treatment }\end{array}$ & Biotype & $\begin{array}{c}\text { Asymptotic } \\
\text { Population Growth } \\
\text { Rate }(\lambda)\end{array}$ \\
\hline \multirow[t]{6}{*}{2012} & \multirow[t]{2}{*}{$\mathrm{CS}$} & $\mathrm{H}$ & $1.833(0.222)$ \\
\hline & & W & $1.850(0.263)$ \\
\hline & \multirow[t]{2}{*}{ DR } & $\mathrm{H}$ & $2.372(0.485)$ \\
\hline & & $\mathrm{W}$ & $1.573(0.041)$ \\
\hline & \multirow[t]{2}{*}{ LR } & $\mathrm{H}$ & $2.423(0.447)$ \\
\hline & & $\mathrm{W}$ & $1.943-$ \\
\hline \multirow[t]{6}{*}{2013} & \multirow[t]{2}{*}{$\mathrm{CS}$} & $\mathrm{H}$ & $2.892(0.960)$ \\
\hline & & $\mathrm{W}$ & $1.796(0.083)$ \\
\hline & \multirow[t]{2}{*}{ DR } & $\mathrm{H}$ & $2.753(0.475)$ \\
\hline & & $\mathrm{W}$ & $1.333(0.102)$ \\
\hline & \multirow[t]{2}{*}{ LR } & $\mathrm{H}$ & $2.316(0.249)$ \\
\hline & & $\mathrm{W}$ & $2.942-$ \\
\hline
\end{tabular}


Table 3.3.4: The average values of select vital rates of $R$. raphanistrum wild (W) and $R$. raphanistrum $\mathrm{x}$ R. sativus hybrid (H) over two growing seasons (2012 and 2013) under three watering treatments [control shelter (CS), double rain (DR), low rain (LR)] in King City, ON. Maximum sample size of plants in an averaged plot is denoted by ' $n$ '. Dormancy and emergence values represent a proportion of seeds from the estimated total (and are originally presented in Ch. 2); survival to non-flowering adult and flowering represent the proportion of individuals that survived from the previous stage. Standard errors are in parentheses. Control unsheltered treatment excluded from watering treatment due to low sample size. 
Table 3.3.4:

\begin{tabular}{|c|c|c|c|c|c|c|c|c|}
\hline Year & $\begin{array}{c}\text { Watering } \\
\text { Treatment }\end{array}$ & Biotype & $\begin{array}{l}\text { Sample } \\
\text { Size (n) }\end{array}$ & Dormancy & Emergence & $\begin{array}{c}\text { Survival } \\
\text { to Non- } \\
\text { flowering } \\
\text { Adult }\end{array}$ & $\begin{array}{c}\text { Survival } \\
\text { to } \\
\text { Flowering }\end{array}$ & $\begin{array}{l}\text { Average } \\
\text { Seeds/Plant } \\
\text { (SE) }\end{array}$ \\
\hline \multirow[t]{6}{*}{2012} & \multirow[t]{2}{*}{$\mathrm{LR}$} & $\mathrm{H}$ & 62 & 0.11 & 0.42 & 0.85 & 0.82 & $157.33(97.4)$ \\
\hline & & W & 40 & 0.31 & 0.27 & 0.80 & 0.88 & $275.00(-)$ \\
\hline & \multirow[t]{2}{*}{ CS } & $\mathrm{H}$ & 56 & 0.16 & 0.40 & 0.94 & 0.83 & $262.50(216.5)$ \\
\hline & & W & 64 & 0.34 & 0.10 & 0.79 & 0.86 & $165.67(90.2)$ \\
\hline & \multirow[t]{2}{*}{ DR } & $\mathrm{H}$ & 67 & 0.14 & 0.24 & 0.94 & 0.86 & $286.00(168.4)$ \\
\hline & & W & 62 & 0.19 & 0.05 & 0.92 & 0.89 & $49.00(19.0)$ \\
\hline \multirow[t]{6}{*}{2013} & \multirow[t]{2}{*}{ LR } & $\mathrm{H}$ & 54 & 0.10 & 0.37 & 0.99 & 0.77 & $165.33(104.5)$ \\
\hline & & W & 50 & 0.29 & 0.21 & 0.96 & 0.96 & $62.00(-)$ \\
\hline & \multirow[t]{2}{*}{$\mathrm{CS}$} & $\mathrm{H}$ & 63 & 0.23 & 0.36 & 0.96 & 0.88 & $36.00(17.0)$ \\
\hline & & W & 69 & 0.26 & 0.14 & 0.92 & 0.92 & $74.33(33.6)$ \\
\hline & \multirow[t]{2}{*}{ DR } & $\mathrm{H}$ & 59 & 0.14 & 0.47 & 0.98 & 0.81 & $100.00(43.2)$ \\
\hline & & W & 67 & 0.17 & 0.22 & 0.94 & 0.88 & $31.00(6.0)$ \\
\hline
\end{tabular}




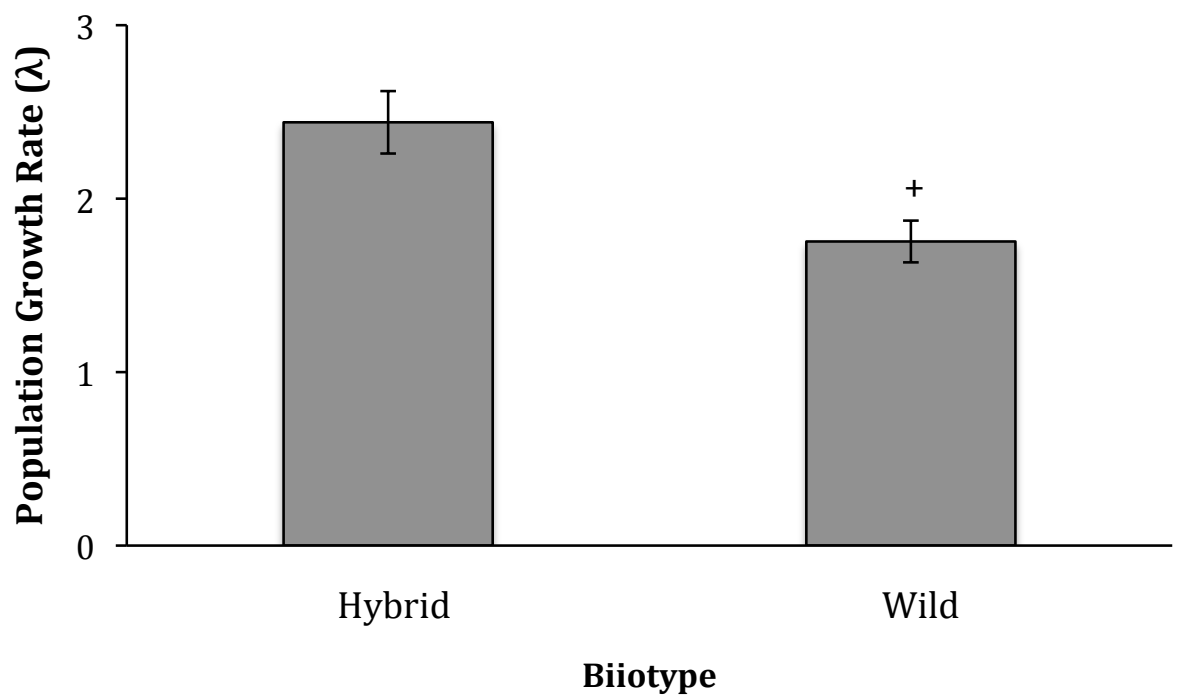

Figure 3.3.1: Comparison of average asymptotic population growth rates $(\lambda)$ averaged over years $(2012,2013)$ of wild $(n=14)$ and crop-wild hybrid $(n=16)$ populations of Raphanus grown under various watering treatments (low rain, control shelter, double rain) in King City, ON (+/- SE). Significance between biotypes is denoted by $+\mathrm{P}<0.1$, * $\mathrm{P}<0.05,{ }^{* *} \mathrm{P}<0.01, * * * \mathrm{P}<0.001$. 


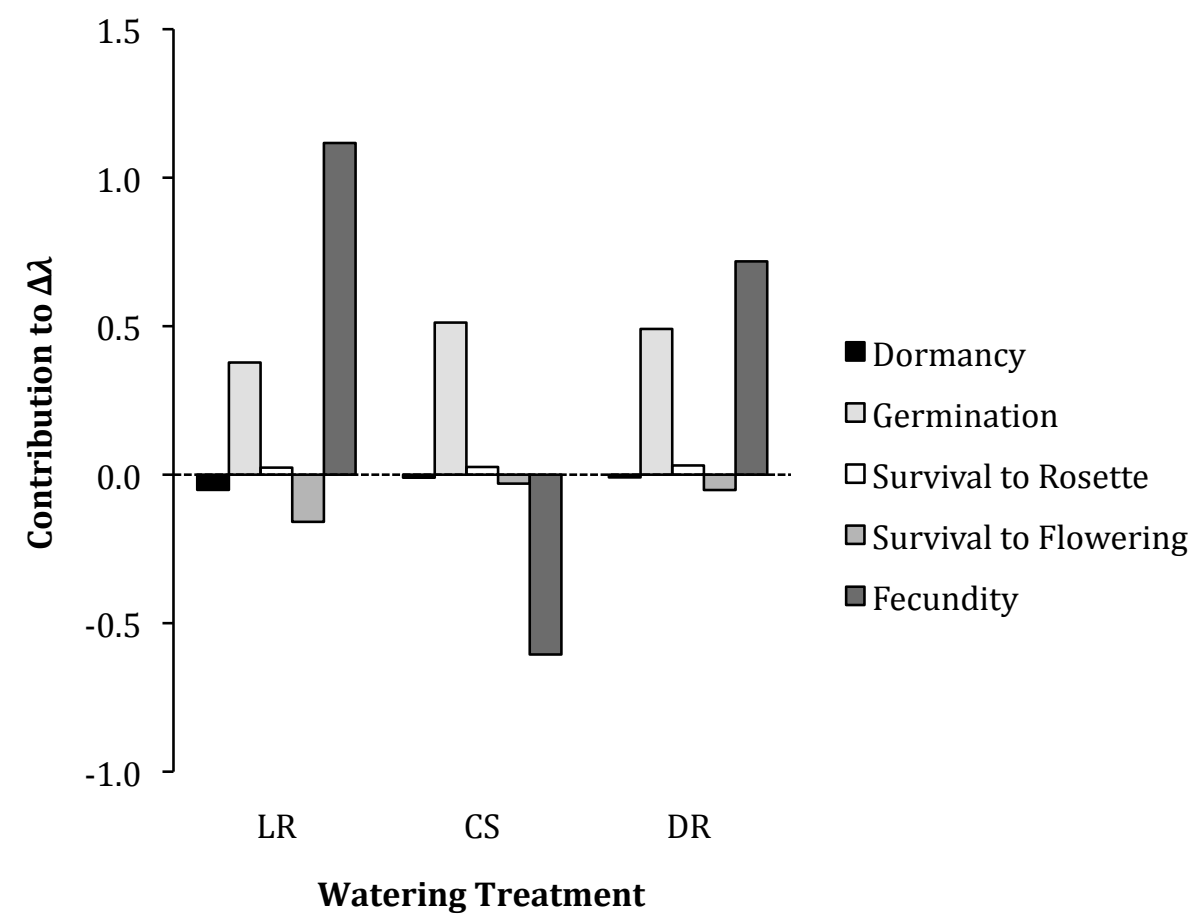

Figure 3.3.2: Contributions from dormancy, germination, survival to non-flowering adult, survival to flowering, and fecundity vital rates of Raphanus, to differences between hybrid and wild biotype population growth rates $(\Delta \lambda)$, under three watering treatments [control shelter (CS), double rain (DR), low rain (LR)], grown in King City, ON. A 'contribution' from a vital rate is calculated as the 'difference' in corresponding matrix elements (wild - hybrid), weighted by its 'sensitivity' to describe how lambda changes with different vital rates. 


\section{$\underline{3.4 \text { Discussion }}$}

\subsubsection{Hybridization Increases Weediness}

At Koffler Scientific Reserve, populations of hybrid radish grew faster than wild populations regardless of their soil moisture environment. Hybrid lineages can have greater fitness than their parental biotypes (Arnold 1997; Arnold et al. 2001; Hooftman et al. 2005; Yang et al. 2011), and crop-wild hybridization can lead to phenotypicallybeneficial heterospecific gene interactions from interspecific mating (Rieseberg et al. 1996; Gardner et al. 2000) to increase population growth. Only hybrids from 2011-2012 experienced greater $r$ than wilds, not those from 2012-2013, suggesting that $\mathrm{F}_{1}$ hybrids may incur a fitness advantage that subsequent generations lack. It is not uncommon for $\mathrm{F}_{1}$ hybrids to experience heterosis due to favorable epistatic or additive allele combinations, and for later generations to lose this fitness advantage over their parental biotypes (Burke and Arnold 2001; Vogel and Mitchell 2008). In subsequent years following the initial hybridization step, genetic linkage can cause favourable gene combinations to be broken up and/or created, affecting the means and variances of demographic traits. For hybrid populations to persist, the newly combined genetic architecture must allow for the inheritance of favorable genes, as natural selection must act on the offspring of relatively fit individuals as well as their parents (Barton 2001). In Raphanus, advanced-generation hybrid plants with persistent crop alleles had greater fecundity and survival than wild plants grown in California but not Michigan (Campbell et al. 2006), which could lead to greater long-term population growth rate. Similarly, crop-wild hybrid radish populations outcompeted wild radish when grown in a Texan novel habitat, though was able to do so with life-history traits other than fecundity (Hovick et al. 2012). 


\subsubsection{Environment Affects Weediness}

Both biotic and abiotic interactions can alter hybrid radish population growth. Hybrid populations had greater population growth than wild populations when grown with greater intraspecific competition (Campbell and Snow 2007; Campbell et al. 2014); hybrid populations have had higher fecundities than its progenitors in certain environments (Ridley and Ellstrand 2009). In this experiment, only $\mathrm{F}_{2-3}$ plants under drought conditions experienced a shrinking $r$ compared to other climate change scenario populations' growing $r$, but this trend reversed for $\mathrm{F}_{3-4}$. This result suggests that initial population responses to drought stress may be inflated in either direction, but will stabilize over time (Chaves et al. 2003). Other than this wrinkle, my results do not reveal that diminished or enhanced water supply will affect $\lambda$. Results comparing soil moisture among plots indicate that watering treatments created a deliberate gradient among plots over several years (see Chapter 2). I may have seen greater significance in $\lambda$ among treatments had there been a large enough seed-bank sample size to include more replication, or if the drought treatments were even more extreme in duration. Contrary to my results, the literature shows numerous examples of plant demographic parameters sensitively responding to changes in precipitation (Freas and Kemp 1983; Herrera 1991; Petru et al. 2006; Lucas et al. 2008; Zhu et al. 2014). Whereas drought conditions will sometimes cause extensive mortality in weed species over crops (Blackman and Templeman 1938), my results did not reveal any genotype by environment interaction on $\lambda$. 
Closely tied to precipitation is geographical location. Wild radish occurs in all continents but Antarctica where varying selection regimes controlled by climate, pollination and herbivory have led to local adaptation (Sahli et al. 2008). The strength of precipitation selection in my experiment, though imposed for few generations, may have contributed to contrasting $\lambda$ over years. Hybrids have invaded California in the last 50 years, where $R$. raphanistrum used to be dominant (Snow et al. 2001; Hegde et al. 2006), but do not occur in Australia, where $R$. raphanistrum is a problematic weed (Cheam and Code 1995). In drier climates than southern Ontario, such as California and Australia, Raphanus is an extremely problematic weed, perhaps because of its ability to outcompete other flora when drought stressed. Indeed, regional habitat, even if novel to the biotype, can play a significant role in determining both wild and hybrid success (Clements et al. 2004; Hovick et al. 2012). Given the multitude of environmental variables that dictate the founding and persistence of plant populations, future work should test for effects of temperature and light on relative success between Raphanus biotypes.

\subsubsection{Contributions from Vital Rates}

Although population growth rates $(\lambda)$ were only marginally significantly different between biotypes, I found, upon closer examination of contributions to lambda, that biotypes attain similar growth rates using different life-history strategies. Rates of germination and survival-to-rosette boosted $\lambda$ of hybrid populations, whereas rates of dormancy and survival-to-flowering boosted $\lambda$ of wild populations. These results satisfy my prediction that crop seed banks are expected to have synchronous and heightened rates of germination, as well as minimal dormancy, due to continuous selection on these 
crop-friendly traits (Koller 1972; Seiler 1992). In contrast, wild populations are subject to a wider range of environmental conditions not controlled by humans and can respond to unfavorable growth conditions through prolonged dormancy and staggered emergence (Lawson et al. 1974; Teo-Sherrell 1996). Selection for select, optimal life-history traits, could potentially result in tradeoffs with other traits. Though data is scarce, there is some evidence that annual weed species particularly suffer from post-emergence mortality (Boutin and Harper 1991). When compared to crop species, they have far fewer seed reserves to rely on during emergence and establishment (Mohler 1996), defined as the period between flowering and growth of a first true leaf. Thus, the relative importance of seed dormancy function is crucial for weed propagation strategy. The relative growth rate (RGR) of a plant declines with crop-like seeds, (Chapin et al. 1989; Seibert and Pearce 1993). Thus, the initial size advantage for cultivated plants is lost once small-seeded weeds catch up in size to crop competitors (Seibert and Pearce 1993; Mohler 1996). If weeds can survive past the seedling stage, their mortality drastically declines (Naylor 1972; Mack and Pyke 1983; Mohler 2001), which may further explain the contrasting life-history contributions between wild and crop-wild hybrid radish.

\subsubsection{Implications for Weed Management}

Weed management strategies are specific to the crop and weed system and most often target a specific life-history stage under particular environmental conditions. The importance of LTRE as a tool to identify best-practice weed management strategies is highlighted by my results, in which the vital rate of fecundity contributes to differences between wild and hybrid $\lambda$ to a greater extent than any other life-history vital rate. This 
crucial trait is only beneficial for hybrid plants compared to wild plants when populations are either drought stressed or inundated with water, not when under average precipitation conditions. Therefore, farmers, who have some level of control over how much water their fields receive via irrigation can be better informed about when to attack weed populations and which watering conditions are best suited for their eradication, while minimally harming their own crops. For instance, farmers wishing to deter wild $R$. raphanistrum population growth in their fields may avoid irrigation during the weed's germination and seed-set phases (see Figure 3.3.2).

It is important for weed management strategies to be considered at a speciesspecific level, and to incorporate many components of plant fitness. One LTRE assessed climate-change scenarios on the perennial Cryptantha flava demography, and found that survival and growth vital rates negatively influenced drought populations relative to controls, but not fecundity, as would be expected for a perennial plant (Lucas et al. 2008). Their study also reveals the crucial influence of the timing of precipitation on seedling emergence and establishment (Lucas et al. 2008). Though other climatic variables would better illuminate weed-management strategies for land managers, this study highlights the utility of demographic data to account for fitness over the entire plant's life history. Data on seed germination, dormancy and mortality is often ignored in other LTREs due to the difficult nature of tracking seedbanks, though without this data, my incomplete model would have revealed strikingly different trends. 


\section{CHAPTER 4. DISCUSSION}

\section{$\underline{4.1 \text { Summary }}$}

My thesis set out to assess the potential effect of soil moisture variation on the relative invasiveness of Raphanus crop-wild hybrids plants or populations and their weedy parents. To this end, I measured the response of several demographic parameters over two generations and found some evidence of increased invasiveness of hybrid versus wild populations as well as a genetic by environment effect. There are many examples in the literature where wild plants are outcompeted by their hybrid progenitors when a single demographic parameter is compared (e.g., Ellstrand 2003; Fuchs et al. 2004; Hooftman et al. 2005; Mercer et al. 2006; Yang et al. 2011). My thesis is novel in that it amalgamates many of these demographic parameters to be viewed as whole as well as on their own. Previously, in Campbell et al. (2014), I tested all crucial life-history components between Raphanus biotypes except for seed related vital rates. Here I incorporate measures of seed germination, dormancy and mortality into my LTRE. I also explore demography across a water gradient in these experiments to better understand contextual weediness in future agricultural scenarios. My results highlight the advantage that hybrid populations have over wild populations when growing in severely altered levels of soil moisture, as new climate tends predict (Jentsch et al. 2007; IPCC 2012). Genotype by environment interactions are well documented (e.g. Campbell and Waser 2001; Campbell et al. 2006; Campbell and Snow 2007; Mercer et al. 2007), and precipitation is a crucial factor in the success of many competing species (Goldberg 1990). Demographic responses were dynamic over time and varied considerably in degree and direction depending on the trait I examined. For land managers to be 
successful in controlling spread and persistence of weed species, they must factor in the abiotic environment to forecast the intensity of the eradication plan. As well, they must target the most vulnerable stage of a plant's life cycle with particular timing, when formulating an eradication plan. Below, I discuss practical implications that this body of work can contribute to the agricultural systems that will be challenged by altering precipitation patterns via global change.

\section{$\underline{4.2 \text { Global Agriculture Problems }}$}

Increasingly high-quality food demands of a rapidly growing human population require an expansion of agricultural operations that could seriously risk environmental integrity (NRC 2003). Modern agricultural operations require vast tracts of limited land; globally, at least 13 million ha of mainly forested land are converted into grazing or cropping fields every year (FAO 2002). As food production continually fails to meet the growing human population requirements, it may become more difficult to produce food, especially in the face of global climate change, which is altering agricultural ecosystems (Reilly et al. 1994). While some regions of crop-land may in fact benefit from global climate change in the short term due to greater growing potential in warmer northern latitudes (Rosenzweig et al. 2002), irregular weather can make crops susceptible to expanded geographic ranges of pests, diseases, and weeds (Rosenzweig et al. 2001). Consequently, there has been a push to modify static farming protocols, which would integrate ecological research from the population, community and ecosystem level into cropland management strategies (PinstrupAndersen and PandyaLorch 1996; Tilman et al. 2002; Foley et al. 2011). 
To reduce crop yield losses, farmers have limited but effective means to control weed infestations, including an array of strategies in Integrated Pest Management (IPM) (Kogan 1998; Norris and Kogan 2000; Ellsworth and Martinez-Carrillo 2001). Examples if IPM, such as crop rotation and tilling strategies can reduce crop competition for water, sunlight and nutrients. Much effort has been poured into developing chemical herbicides, but they can cause severe environmental degradation (Liebman and Dyck 1993; Rohr et al. 2004; Rohr et al. 2013; St Clair and Fuller 2014) and herbicide resistance is increasingly common, making this singular approach a non-viable long-term solution (Roush et al. 1990; Heap 1997). Using organic farming protocols in place of herbicides will likely drastically lower yields (Bond and Grundy 1998; Albrecht 2005), and so further research is required to both increase crop yields and to de-escalate ecological risk.

\section{$\underline{4.3 \text { Weed-management Strategies }}$}

The timing and intensity of weed emergence outbreaks varies considerably with weather and region, though accurately predicting these trends from relatively short-term studies can be challenging (Lawson et al. 1974). Further examination of the few longterm datasets reveal that seasonal patterns of germination, dormancy, survival and fecundity predictably interact with climate trends (Roberts and Feast 1970; Grundy 2001). I predict that climate change will most directly affect fecundity compared to other vital rates, due to the dependence of seed set on water resources and temperature. Of the meteorological factors modeled, temperature is the greatest predictor for long-term weed emergence, followed by soil moisture (Grundy and Mead 2000). Precipitation events interact with the timing of human cultivation practices to influence weed emergence 
(Roberts and Potter 1980). Studies, such as mine, which provide contextual patterns in timing of emergence, seedbank persistence, life-stage vulnerabilities, and long-term population growth with climatic variables, are important for use as predictive tools. Climate modeling projections allow for regional differentiation in natural rainfall to be used to farmers' advantage. Using this information, farmers can optimally control the application of irrigation, the timing of their cultivation and their use of weedmanagement tools, to prevent long-lasting weed population persistence (Ogg and Dawson 1984; Forcella 1993).

\section{$\underline{4.4 \text { Future Work }}$}

I chose to analyze my demographic data using an LTRE approach, which allowed me to break down the complex life history of Raphanus spp. into its dynamic vital rates, represented cyclically in a matrix model (i.e. seeds produced at the end of one plant's life history from a current generation feed into subsequent generations' life histories). Utilizing new developments in life-history analysis, such as Aster modeling may have enhanced the accuracy of my results, by recognizing that my life-history data as a whole does not fit any common statistical distribution (Geyer et al. 2007). Rather, dormancy, emergence, survival to various stages, and fecundity all have different probability distributions but are dependant on each other. Assessment on fewer fitness components than this would have revealed incomplete, alternate results (Hooftman et al. 2005). Aster models account for heterogenous probability distributions that are conditionally dependant (Geyer et al. 2007). My study species is an annual plant, and thus individual

plants have zero reproductive potential in subsequent years. As such, my matrix modeling 
protocol adequately captured multiple components of plant fitness to give long-term population growth rate values, though acyclic Aster models may have revealed more accurate results based on conditional dependence of vital rates.

Also, mimicking agricultural scenarios, tillage of our plots was expected to significantly increase germination and decrease competition rates. Using a different variety of the many tilling methods available, or not tilling at all, would likely impact these factors. Long-term tillage provides a constant selection pressure over time, which may render dormancy of little adaptive value to plant life-history strategy. Future work should assess rates of seed dormancy over a longer time frame in both tilled and on-tilled environments.

\section{$\underline{4.5 \text { Conclusion }}$}

Building on previous work from Campbell et al. (2014), this body of work penetrated into the dynamics of invasive weed biology to understand the consequences of crop-wild hybridization of Raphanus spp. in natural settings. I assessed below- and above-ground demographic population parameters of this system in the field over a soil moisture gradient to account for climate change projections. Results are discussed in the context of use as an agricultural predictive tool for weed management. Future work should experiment with alternate modeling techniques and explore additional influential climatic factors. 


\section{APPENDIX}

\section{$\underline{\text { Definitions }}$}

$\lambda$ : asymptotic population growth rate; dominant eigenvalue

ANOVA: analysis of variance

CS: control sheltered

CU: control unsheltered

DR: Double Rain

$\mathrm{H}$ : crop wild hybrid radish (R. raphanistrum $\mathrm{x}$ R. sativus)

IPM: Integrated Pest Management

KSR: Koffler Scientific Reserve at Jokers Hill, King City, ON, Canada

LR: low rain

LTRE: Life Table Response Experiment

MANOVA: multivariate analysis of variance

$r$ : instrinsic population growth rate

$\mathrm{W}$ : wild radish ( $R$. raphanistrum) 


\section{LITERATURE CITED}

Adkins, S. W., J. M. Naylor, and G. M. Simpson. 1984. The physiological basis of seed dormancy in Avena fatua V. Action of ethanol and other organic compounds. Physiologia Plantarum 62:18-24.

Adler, L. S., K. Wikler, F. S. Wyndham, C. R. Linder, and J. Schmitt. 1993. Potential for persistence of genes escaped from canola: germination cues in crop, wild, and crop-wild hybrid Brassica rapa. Functional Ecology 7:736-745.

Albrecht, H. 2005. Development of arable weed seedbanks during the 6 years after the change from conventional to organic farming. Weed Research 45:339350.

Allen, P. S. and S. E. Meyer. 1998. Ecological aspects of seed dormancy loss. Seed Science Research 8:183-191.

Arias, D. M. and L. H. Rieseberg. 1994. Gene flow between cultivated and wild sunflowers. Theoretical and Applied Genetics 89:655-660.

Arnold, M. L. 1997. Natural hybridization and evolution. Oxford University Press, New York.

Arnold, M. L., E. K. Kentner, J. A. Johnston, S. Cornman, and A. C. Bouck. 2001. Natural hybridisation and fitness. Taxon 50:93-104.

Arnold, R. L. B., M. Fenner, and P. J. Edwards. 1992. Changes in dormancy level in Sorghum halepense seeds induced by water stress during seed development. Functional Ecology 6:596-605.

Baack, E. J., Y. Sapir, M. A. Chapman, J. M. Burke, and L. H. Rieseberg. 2008. Selection on domestication traits and quantitative trait loci in crop-wild sunflower hybrids. Molecular Ecology 17:666-677.

Baker, H. G. 1965. Characteristics and modes of origin of weeds. Pp. 147-172 in H. G. Baker, and G. L. Stebbins, eds. The genetics of colonizing species. Academic Press, New York, NY.

Barnett, T. P., J. C. Adam, and D. P. Lettenmaier. 2005. Potential impacts of a warming climate on water availability in snow-dominated regions. Nature 438:303309.

Barrett, S. C. H. 1983. Crop mimicry in weeds. Economic Botany 37:255-282.

Barton, N. H. 2001. The role of hybridization in evolution. Molecular Ecology 10:551-568.

Barton, N. H. and G. M. Hewitt. 1985. Analysis of hybrid zones. Annual Review of Ecology and Systematics 16:113-148.

Baskin, C. C. 2003. Breaking physical dormancy in seeds - focussing on the lens. New Phytologist 158:229-232.

Baskin, C. C. and J. M. Baskin. 1988. Germination ecophysiology of herbaceous plant species in a temperate region. American Journal of Botany 75:286-305.

Baskin, C. C. and J. M. Baskin. 2001. Seeds: ecology, biogeography, and evolution of dormancy and germination. Academic Press, San Diego, CA.

Baskin, J. M. and C. C. Baskin. 1974. Some eco-physiological aspects of seed dormancy in Geranium carolinianum L. from central Tennessee. Oecologia 16:209-219. 
Baskin, J. M. and C. C. Baskin. 2004. A classification system for seed dormancy. Seed Science Research 14:1-16.

Benton, T. G. and A. Grant. 1999. Elasticity analysis as an important tool in evolutionary and population ecology. Trends in Ecology \& Evolution 14:467471.

Bergelson, J. 1994. Changes in fecundity do not predict invasiveness: a model study of transgenic plants. Ecology 75:249-252.

Blackman, G. E. and W. G. Templeman. 1938. The nature of the competition between cereal crops and annual weeds. Journal of Agricultural Science 28:247-271.

Blair, A. C., D. Blumenthal, and R. A. Hufbauer. 2012. Hybridization and invasion: an experimental test with diffuse knapweed (Centaurea diffusa Lam.). Evolutionary Applications 5:17-28.

Bond, W. and A. C. Grundy. 1998. Desk study on the control of weeds in organic arable and horticultural production systems. Project Report OF 0152. MAFF, London, UK.

Bone, E. and A. Farres. 2001. Trends and rates of microevolution in plants. Genetica 112:165-182.

Boutin, C. and J. L. Harper. 1991. A comparative study of the population dynamics of 5 species of Veronica in natural habitats. Journal of Ecology 79:199-221.

Bouwmeester, H. J. and C. M. Karssen. 1993. Seasonal periodicity in germination of seeds of Chenopodium album L. Annals of Botany 72:463-473.

Bradshaw, A. D. 1984. Citation classic - Evolutionary significance of phenotypic plasticity in plants. Current Contents/Agriculture Biology \& Environmental Sciences:20-20.

Brault, S. and H. Caswell. 1993. pod-specific demography of killer whales (Orcinus orca). Ecology 74:1444-1454.

Brodersen, C., S. Lavergne, and J. Molofsky. 2008. Genetic variation in photosynthetic characteristics among invasive and native populations of reed canarygrass (Phalaris arundinacea). Biological Invasions 10:1317-1325.

Bullock, J. M. 1999. Using population matrix models to target GMO risk assessment. Aspects of Applied Biology 53:205-212.

Burke, J. M. and M. L. Arnold. 2001. Genetics and the fitness of hybrids. Annual Review of Genetics 35:31-52.

Campbell, D. R. and N. M. Waser. 2001. Genotype-by-environment interaction and the fitness of plant hybrids in the wild. Evolution 55:669-676.

Campbell, L. G., J. Luo, and K. L. Mercer. 2013. Effect of water availability and genetic diversity on flowering phenology, synchrony and reproductive investment in summer squash. Journal of Agricultural Science 151:775-786.

Campbell, L. G. and A. A. Snow. 2007. Competition alters life history and increases the relative fecundity of crop-wild radish hybrids (Raphanus spp.). New Phytologist 173:648-660.

Campbell, L. G., A. A. Snow, and C. E. Ridley. 2006. Weed evolution after crop gene introgression: greater survival and fecundity of hybrids in a new environment. Ecology Letters 9:1198-1209.

Campbell, L. G., Z. Teitel, M. N. Miriti, and A. A. Snow. 2014. Context-specific enhanced invasiveness of Raphanus crop-wild hybrids: a test for associations 
between greater fecundity and population growth. Canadian Journal of Plant Science 94:1-10.

Caswell, H. 2001. Matrix Population Models. Sinauer Press, Sunderland, MA.

Chapin, F. S., R. H. Groves, and L. T. Evans. 1989. Physiological determinants of growth rate in response to phosphorus supply in wild and cultivated Hordeum species. Oecologia 79:96-105.

Chaves, M. M., J. P. Maroco, and J. S. Pereira. 2003. Understanding plant responses to drought - from genes to the whole plant. Functional Plant Biology 30:239264.

Cheam, A. H. 1986. Seed production and seed dormancy in wild radish (Raphanus raphanistrum L.) and some possibilities for improving control. Weed Research 26:405-413.

Cheam, A. H. and G. R. Code. 1995. The biology of Australian weeds. 24. Raphanus raphanistrum L. Plant Protection Quarterly 10:2-13.

Chen, L. J., D. S. Lee, Z. P. Song, H. S. Suh, and B. R. Lu. 2004. Gene flow from cultivated rice (Oryza sativa) to its weedy and wild relatives. Annals of Botany 93:67-73.

Cheplick, G. P. 1996. Do seed germination patterns in cleistogamous annual grasses reduce the risk of sibling competition? Journal of Ecology 84:247-255.

Christensen, J. H. and O. B. Christensen. 2003. Climate modelling: Severe summertime flooding in Europe. Nature 421:805-806.

Cleland, E. E., I. Chuine, A. Menzel, H. A. Mooney, and M. D. Schwartz. 2007. Shifting plant phenology in response to global change. Trends in Ecology \& Evolution 22:357-365.

Clements, D. R., A. DiTommaso, N. Jordan, B. D. Booth, J. Cardina, D. Doohan, C. L. Mohler, S. D. Murphy, and C. J. Swanton. 2004. Adaptability of plants invading north American cropland. Agriculture Ecosystems \& Environment 104:379398.

Cohen, D. 1966. Optimizing reproduction in a randomly varying environment. Journal of Theoretical Biology 12:119-\&.

Cohen, D. 1968. A general model of optimal reproduction in a randomly varying environment. Journal of Ecology 56:219-\&.

Colautti, R. I. and H. J. MacIsaac. 2004. A neutral terminology to define 'invasive' species. Diversity and Distributions 10:135-141.

Conner, J. and S. Via. 1993. Patterns of phenotypic and genetic correlations among morphological and life-history traits in wild radish, Raphanus raphanistrum. Evolution 47:704-711.

Conner, J. K., S. Rush, and P. Jennetten. 1996. Measurements of natural selection on floral traits in wild radish (Raphanus raphanistrum). I. Selection through lifetime female fitness. Evolution 50:1127-1136.

Cousens, R. D., K. R. Young, and A. Tadayyon. 2010. The role of the persistent fruit wall in seed water regulation in Raphanus raphanistrum (Brassicaceae). Annals of Botany 105:101-108.

Dewet, J. M. J. 1975. Symposium on biochemical systematics, genetics and origin of cultivated plants II. Evolutionary dynamics of cereal domestication. Bulletin of the Torrey Botanical Club 102:307-312. 
Dore, M. H. I. 2005. Climate change and changes in global precipitation patterns: What do we know? Environment International 31:1167-1181.

Duddu, H. S. and S. J. Shirtliffe. 2014. Variation of Seed Dormancy and Germination Ecology of Cowcockle (Vaccaria hispanica). Weed Science 62:483-492.

Dukes, J. S. and H. A. Mooney. 1999. Does global change increase the success of biological invaders? Trends in Ecology \& Evolution 14:135-139.

Ellstrand, N. C. 2003. Dangerous liaisons?: when cultivated plants mate with their wild relatives. . JHU Press.

Ellstrand, N. C., S. M. Heredia, J. A. Leak-Garcia, J. M. Heraty, J. C. Burger, L. Yao, S. Nohzadeh-Malakshah, and C. E. Ridley. 2010. Crops gone wild: evolution of weeds and invasives from domesticated ancestors. Evolutionary Applications 3:494-504.

Ellstrand, N. C. and D. L. Marshall. 1985. Interpopulation gene flow by pollen in wild radish, Raphanus sativus. American Naturalist 126:606-616.

Ellstrand, N. C., H. C. Prentice, and J. F. Hancock. 1999. Gene flow and introgression from domesticated plants into their wild relatives. Annual Review of Ecology and Systematics 30:539-563.

Ellstrand, N. C. and K. A. Schierenbeck. 2000. Hybridization as a stimulus for the evolution of invasiveness in plants? Proceedings of the National Academy of Sciences of the United States of America 97:7043-7050.

Ellstrand, N. C. and K. A. Schierenbeck. 2006. Hybridization as a stimulus for the evolution of invasiveness in plants? Euphytica 148:35-46.

Ellsworth, P. C. and J. L. Martinez-Carrillo. 2001. IPM for Bemisia abaci: a case study from North America. Crop Protection 20:853-869.

Emms, S. K. and M. L. Arnold. 1997. The effect of habitat on parental and hybrid fitness: Transplant experiments with Louisiana irises. Evolution 51:11121119.

Eslami, S. V., G. S. Gill, B. Bellotti, and G. McDonald. 2006. Wild radish (Raphanus raphanistrum) interference in wheat. Weed Science 54:749-756.

Eslami, S. V., G. S. Gill, and G. McDonald. 2010. Effect of water stress during seed development on morphometric characteristics and dormancy of wild radish (Raphanus raphanistrum L.) seeds. International Journal of Plant Production 4:159-168.

Evenari, M. 1965. Light and seed dormancy. Springer, Berlin Heidelberg.

FAO. 2002. FAOSTAT Statistics Database. UN Food and Agriculture Organization., Rome, Italy.

Finch-Savage, W. E. and G. Leubner-Metzger. 2006. Seed dormancy and the control of germination. New Phytologist 171:501-523.

Foley, J. A., N. Ramankutty, K. A. Brauman, E. S. Cassidy, J. S. Gerber, M. Johnston, N. D. Mueller, C. O'Connell, D. K. Ray, P. C. West, C. Balzer, E. M. Bennett, S. R. Carpenter, J. Hill, C. Monfreda, S. Polasky, J. Rockstrom, J. Sheehan, S. Siebert, D. Tilman, and D. P. M. Zaks. 2011. Solutions for a cultivated planet. Nature 478:337-342.

Forcella, F. 1993. Seedling emergence model for velvetleaf. Agronomy Journal 85:929-933. 
Forcella, F. 1998. Real-time assessment of seed dormancy and seedling growth for weed management. Seed Science Research 8:201-209.

Franks, S. J., S. Sim, and A. E. Weis. 2007. Rapid evolution of flowering time by an annual plant in response to a climate fluctuation. Proceedings of the National Academy of Sciences of the United States of America 104:1278-1282.

Freas, K. E. and P. R. Kemp. 1983. Some relationships between environmental reliability and seed dormancy in desert annual plants. Journal of Ecology 71:211-217.

Freeman, M. F. and J. W. Tukey. 1950. Transformations related to the angular and the square root. Ann. Math. Statst. 21:607-611.

Fuchs, M., E. M. Chirco, J. R. McFerson, and D. Gonsalves. 2004. Comparative fitness of a wild squash species and three generations of hybrids between wild $\mathrm{x}$ virus-resistant transgenic squash. Environmental biosafety research 3:17-28.

Gardner, K., A. Buerkle, J. Whitton, and L. Rieseberg. 2000. Inferring epistasis in wild sunflower hybrid zones Pp. 264-279. Epistasis and the Evolutionary Process. Oxford Univ. Press, Oxford.

Garwood, N. C. 1983. Seed germination in a seasonal tropical forest in Panama: a community study. Ecological Monographs 53:159-181.

Gepts, P. 2004. Crop domestication as a long-term selection experiment. Plant breeding reviews 24:1-44.

Geyer, C. J., S. Wagenius, and R. G. Shaw. 2007. Aster models for life history analysis. Biometrika 94:415-426.

Goldberg, D. E. 1990. Components of resource competition in plant communities. Pp. 27-49. Perspectives on plant competition.

Gould, F. 1995. Comparisons between resistance management strategies for insects and weeds. Weed Technology 9:830-839.

Gressel, J. 2005. Introduction - The challenges of ferality. Crop Ferality and Volunteerism:1-7.

Grundy, A. C. 2001. Weed emergence and the weather. Pp. 75-82. Bcpc Conference Weeds 2001, Vols 1 and 2.

Grundy, A. C. and A. Mead. 2000. Modeling weed emergence as a function of meteorological records. Weed Science 48:594-603.

Gutierrez, A., M. Cantamutto, and M. Poverene. 2011. Persistence of sunflower crop traits and fitness in Helianthus petiolaris populations. Plant Biology 13:821830.

Gutterman, Y. and M. Evenari. 1994. The influences of amounts and distribution of irrigation during the hot and dry season on emergence and survival of some desert winter annual plants in the Negev desert. Israel Journal of Plant Sciences 42:1-14.

Hartman, Y., D. A. P. Hooftman, B. Uwimana, C. C. M. van de Wiel, M. J. M. Smulders, R. G. F. Visser, and P. H. van Tienderen. 2012. Genomic regions in crop-wild hybrids of lettuce are affected differently in different environments: implications for crop breeding. Evolutionary Applications 5:629-640.

Heap, I. M. 1997. The occurrence of herbicide-resistant weeds worldwide. Pesticide Science 51:235-243. 
Hegde, S. G., J. D. Nason, J. M. Clegg, and N. C. Ellstrand. 2006. The evolution of California's wild radish has resulted in the extinction of its progenitors. Evolution 60:1187-1197.

Hepher, A. and J. A. Roberts. 1985. The control of seed germination in Trollius ledebouri A model of seed dormancy. Planta 166:321-328.

Herrera, C. M. 1991. Dissecting factors responsible for individual variation in plant fecundity. Ecology 72:1436-1448.

Hierro, J. L., J. L. Maron, and R. M. Callaway. 2005. A biogeographical approach to plant invasions: the importance of studying exotics in their introduced and native range. Journal of Ecology 93:5-15.

Holm, L. G., J. Doll, E. Holm, J. Pancho, and J. Herberger. 1997. World weeds: natural histories and distributions John Wiley and Sons, New York, NY.

Hooftman, D. A. P., J. G. B. Oostermeijer, M. M. J. Jacobs, and H. C. M. Den Nijs. 2005. Demographic vital rates determine the performance advantage of crop-wild hybrids in lettuce. Journal of Applied Ecology 42:1086-1095.

Hou, J. Q., E. J. Kendall, and G. M. Simpson. 1997. Water uptake and distribution in non-dormant and dormant wild oat (Avena fatua $\mathrm{L}$ ) caryopses. Journal of Experimental Botany 48:683-692.

Hovick, S. M., L. G. Campbell, A. A. Snow, and K. D. Whitney. 2012. Hybridization Alters Early Life-History Traits and Increases Plant Colonization Success in a Novel Region. American Naturalist 179:192-203.

IPCC. 2012. Managing the risks of extreme events and disasters to advance cli-mate change adaptation. Cambridge University Press, Cambridge, United Kingdom.

Jacobsen, J. V. and E. Pressman. 1979. Structural study of germination in celery (Apium graveolens L.) seed with emphasis on endosperm breakdown. Planta 144:241-248.

Jarvis, A., A. Lane, and R. J. Hijmans. 2008. The effect of climate change on crop wild relatives. Agriculture Ecosystems \& Environment 126:13-23.

Jarvis, D. I. and T. Hodgkin. 1999. Wild relatives and crop cultivars: detecting natural introgression and farmer selection of new genetic combinations in agroecosystems. Molecular Ecology 8:S159-S173.

Jentsch, A., J. Kreyling, and C. Beierkuhnlein. 2007. A new generation of climatechange experiments: events, not trends. Frontiers in Ecology and the Environment 5:365-374.

Johnson, W. C., L. E. Jackson, O. Ochoa, R. van Wijk, J. Peleman, D. A. St Clair, and R. W. Michelmore. 2000. Lettuce, a shallow-rooted crop, and Lactuca serriola, its wild progenitor, differ at QTL determining root architecture and deep soil water exploitation. Theoretical and Applied Genetics 101:1066-1073.

Jordan, N. R. and J. L. Jannink. 1997. Assessing the practical importance of weed evolution: a research agenda. Weed Research 37:237-246.

Kercher, S. and J. K. Conner. 1996. Patterns of genetic variability within and among populations of wild radish, Raphanus raphanistrum (Brassicaceae). American Journal of Botany 83:1416-1421.

Klinger, T., D. R. Elam, and N. C. Ellstrand. 1991. Radish as a model system for the study of engineered gene escape rates via crop-weed mating. Conservation Biology 5:531-535. 
Klinger, T. and N. C. Ellstrand. 1994. Engineered genes in wild populations: fitness of weed-crop hybrids of Raphanus sativus. Ecological Applications 4:117-120.

Kogan, M. 1998. Integrated pest management: Historical perspectives and contemporary developments. Annual Review of Entomology 43:243-270.

Koller, D. 1969. The physiology of dormancy and survival of plants in desert environments. Symposia of the Society for Experimental Biology 23:449-469.

Koller, D. 1972. Environmental control of seed germination.

Koop, A. L. and C. C. Horvitz. 2005. Projection matrix analysis of the demography of an invasive, nonnative shrub (Ardisia elliptica). Ecology 86:2661-2672.

Langevin, S. A., K. Clay, and J. B. Grace. 1990. The incidence and effects of hybridization between cultivated rice and its related weed red rice (Oryza saliva L.). Evolution 44:1000-1008.

Lawson, H. M., P. D. Waister, and R. J. Stephens. 1974. Patterns of emergence of several important arable weed species. Pp. 121-135. Weed Control in the Northern Environment; Proceedings of a Symposium.

Liebman, M. and E. Dyck. 1993. Weed management: a need to develop ecological approaches. Ecological Applications 3:40-41.

Linhart, Y. B. and M. C. Grant. 1996. Evolutionary significance of local genetic differentiation in plants. Annual Review of Ecology and Systematics 27:237277.

Lucas, R. W., I. N. Forseth, and B. B. Casper. 2008. Using rainout shelters to evaluate climate change effects on the demography of Cryptantha flava. Journal of Ecology 96:514-522.

Ma, F., C. Zhao, R. Milne, M. Ji, L. Chen, and J. Liu. 2010. Enhanced drought-tolerance in the homoploid hybrid species Pinus densata: implication for its habitat divergence from two progenitors. New Phytologist 185:204-216.

Mack, R. N. and D. A. Pyke. 1983. The demography of Bromus tectorum: variation in time and space. Journal of Ecology 71:69-93.

Mallet, J. 2007. Hybrid speciation. Nature 446:279-283.

Marks, M. and S. Prince. 1981. Influence of germination date on survival and fecundity in wild lettuce Lactuca serriola. Oikos 36:326-330.

Mazer, S. J. 1987. Parental effects on seed development and seed yield in Raphanus raphanistrum: implications for natural and sexual selection. Evolution 41:355-371.

McIntyre, G. I. and A. I. Hsiao. 1985. Seed dormancy in Avena fatua. II. Evidence of embryo water content as a limiting factor. Botanical Gazette 146:347-352.

McLaren, K. P. and M. A. McDonald. 2003. The effects of moisture and shade on seed germination and seedling survival in a tropical dry forest in Jamaica. Forest Ecology and Management 183:61-75.

Mercer, K. L., D. A. Andow, D. L. Wyse, and R. G. Shaw. 2007. Stress and domestication traits increase the relative fitness of crop-wild hybrids in sunflower. Ecology Letters 10:383-393.

Mercer, K. L., R. G. Shaw, and D. L. Wyse. 2006. Increased germination of diverse crop-wild hybrid sunflower seeds. Ecological Applications 16:845-854. 
Miranda, J. D., C. Armas, F. M. Padilla, and F. I. Pugnaire. 2011. Climatic change and rainfall patterns: Effects on semi-arid plant communities of the Iberian Southeast. Journal of Arid Environments 75:1302-1309.

Mohler, C. L. 1996. Ecological bases for the cultural control of annual weeds. Journal of Production Agriculture 9:468-474.

Mohler, C. L. 2001. Weed life history: identifying vulnerabilities. Pp. 40-98. Ecological management of agricultural weeds. Cambridge University Press, Cambridge, UK.

Moloney, K. A., C. Holzapfel, K. Tielboerger, F. Jeltsch, and F. M. Schurr. 2009. Rethinking the common garden in invasion research. Perspectives in Plant Ecology Evolution and Systematics 11:311-320.

Moss, R. H., J. A. Edmonds, K. A. Hibbard, M. R. Manning, S. K. Rose, D. P. van Vuuren, T. R. Carter, S. Emori, M. Kainuma, T. Kram, G. A. Meehl, J. F. B. Mitchell, N. Nakicenovic, K. Riahi, S. J. Smith, R. J. Stouffer, A. M. Thomson, J. P. Weyant, and T. J. Wilbanks. 2010. The next generation of scenarios for climate change research and assessment. Nature 463:747-756.

Naylor, J. M. and S. Jana. 1976. Genetic adaptation for seed dormancy in Avena fatua. Canadian Journal of Botany-Revue Canadienne De Botanique 54:306-312.

Naylor, R. E. L. 1972. Aspects of population dynamics of weed Alopecurus myosuroides huds in winter cereal crops. Journal of Applied Ecology 9:127-\&.

Norris, R. F. and M. Kogan. 2000. Interactions between weeds, arthropod pests, and their natural enemies in managed ecosystems. Weed Science 48:94-158.

NRC. 2003. Frontiers in agricultural research. Food, health, environment, and communities. National Academy Press, Washington DC.

O'Gorman, P. A. and T. Schneider. 2009. The physical basis for increases in precipitation extremes in simulations of 21st-century climate change. Proceedings of the National Academy of Sciences of the United States of America 106:14773-14777.

Ogg, A. G. and J. H. Dawson. 1984. Time of emergence of eight weed species. Weed Science 32:327-335.

Palmer, T. N. and J. Ralsanen. 2002. Quantifying the risk of extreme seasonal precipitation events in a changing climate. Nature 415:512-514.

Panetsos, C. A. and H. G. Baker. 1967. The origin of variation in "wild" Raphanus sativus (Cruciferae) in California. Genetica 38:243-274.

Parker, I. M. 2000. Invasion dynamics of Cytisus scoparius: A matrix model approach. Ecological Applications 10:726-743.

Parmesan, C. 2006. Ecological and evolutionary responses to recent climate change. Annual Review of Ecology Evolution and Systematics 37:637-669.

Passioura, J. 2006. Increasing crop productivity when water is scarce - from breeding to field management. Agricultural Water Management 80:176-196.

Patil, V. N. and M. Dadlani. 2009. Tetrazolium test for seed viability and vigour.

Perez-Jones, A., C. A. Mallory-Smith, O. Riera-Lizarazu, C. J. W. Watson, Z. Wang, M. Rehman, and R. S. Zemetra. 2006. Introgression of a strawbreaker foot rot resistance gene from winter wheat into jointed goatgrass. Crop Science 46:2155-2160. 
Peters, N. C. B. 1982. The dormancy of wild oat seed (Avena fatua L.) from plants grown under various temperature and soil moisture conditions. Weed Research 22:205-212.

Petru, M., K. Tielborger, R. Belkin, M. Sternberg, and F. Jeltsch. 2006. Life history variation in an annual plant under two opposing environmental constraints along an aridity gradient. Ecography 29:66-74.

PinstrupAndersen, P. and R. PandyaLorch. 1996. Food for all in 2020: Can the world be fed without damaging the environment? Environmental Conservation 23:226-234.

Pirimova, N., A. J. Parker, and L. G. Campbell. in press. Does altering local water availability for an invasive plant (Raphanus raphanistrum) affect floral morphology and reproductive potential? American Journal of Undergraduate Research:1-15.

Pnueli, L., E. Hallak-Herr, M. Rozenberg, M. Cohen, P. Goloubinoff, A. Kaplan, and R. Mittler. 2002. Molecular and biochemical mechanisms associated with dormancy and drought tolerance in the desert legume Retama raetam. Plant Journal 31:319-330.

Presotto, A., M. Poverene, and M. Cantamutto. 2014. Seed dormancy and hybridization effect of the invasive species, Helianthus annuus. Annals of Applied Biology 164:373-383.

Raju, M. V. S., A. I. Hsiao, and G. I. McIntyre. 1986. Seed dormancy in Avena fatua. III. the effect of mechanical injury on the growth and development of the root and scutellum. Botanical Gazette 147:443-452.

Rees, M. and M. J. Long. 1992. Germination biology and the ecology of annual plants. American Naturalist 139:484-508.

Reeves, T. G., G. R. Code, and C. M. Piggin. 1981. Seed production and longevity, seasonal emergence, and phenology of wild radish (Raphanus raphanistrum L.). Australian Journal of Experimental Agriculture 21:524-530.

Reilly, J., N. Hohmann, and S. Kane. 1994. Climate change and agricultural trade: who benefits, who loses? Global Environmental Change-Human and Policy Dimensions 4:24-36.

Rejmanek, M. 2000. Invasive plants: approaches and predictions. Austral Ecology 25:497-506.

Ridley, C. E. and N. C. Ellstrand. 2009. Evolution of enhanced reproduction in the hybrid-derived invasive, California wild radish (Raphanus sativus). Biological Invasions 11:2251-2264.

Rieseberg, L. H., B. Sinervo, C. R. Linder, M. C. Ungerer, and D. M. Arias. 1996. Role of gene interactions in hybrid speciation: Evidence from ancient and experimental hybrids. Science 272:741-745.

Roberts, E. H. 1962. Dormancy in rice seed: III. Influence of temperature, moisture, and gaseous environment. Journal of Experimental Botany 13:75-\&.

Roberts, H. A. and P. M. Feast. 1970. Seasonal distribution of emergence in some annual weeds. Exp. Hortic. 21:36-41.

Roberts, H. A. and M. E. Potter. 1980. Emergence patterns of weed seedlings in relation to cultivation and rainfall. Weed Research 20:377-386. 
Rohr, J. R., A. A. Elskus, B. S. Shepherd, P. H. Crowley, T. M. McCarthy, J. H. Niedzwiecki, T. Sager, A. Sih, and B. D. Palmer. 2004. Multiple stressors and salamanders: Effects of an herbicide, food limitation, and hydroperiod. Ecological Applications 14:1028-1040.

Rohr, J. R., T. R. Raffel, N. T. Halstead, T. A. McMahon, S. A. Johnson, R. K. Boughton, and L. B. Martin. 2013. Early-life exposure to a herbicide has enduring effects on pathogen-induced mortality. Proceedings of the Royal Society B-Biological Sciences 280.

Root, T. L., J. T. Price, K. R. Hall, S. H. Schneider, C. Rosenzweig, and J. A. Pounds. 2003. Fingerprints of global warming on wild animals and plants. Nature 421:5760.

Rosenzweig, C., A. Iglesias, X. B. Yang, P. R. Epstein, and E. Chivian. 2001. Climate change and extreme weather events; implications for food production, plant diseases, and pests. Global change \& human health 2:90-104.

Rosenzweig, C., F. N. Tubiello, R. Goldberg, E. Mills, and J. Bloomfield. 2002. Increased crop damage in the US from excess precipitation under climate change. Global Environmental Change-Human and Policy Dimensions 12:197-202.

Roush, M. L., S. R. Radosevich, and B. D. Maxwell. 1990. Future outlook for herbicideresistance research. Weed Technology 4:208-214.

Ruyle, G. B., B. A. Roundy, and J. R. Cox. 1988. Effects of burning on germinability of Lehmann lovegrass. Journal of Range Management 41:404-406.

Sahli, H. F., J. K. Conner, F. H. Shaw, S. Howe, and A. Lale. 2008. Adaptive Differentiation of Quantitative Traits in the Globally Distributed Weed, Wild Radish (Raphanus raphanistrum). Genetics 180:945-955.

Sarukhan, J. 1974. Studies on Plant Demography: Ranunculus Repens L, R. Bulbosus L. and R. Acris L.: II. Reproductive Strategies and Seed Population Dynamics. Journal of Ecology 62:151-177.

Schlichting, C. D. 1986. The evolution of phenotypic plasticity in plants. Annual Review of Ecology and Systematics 17:667-693.

Schopfer, P. and C. Plachy. 1993. Photoinhibition of radish (Raphanus sativus L.) seed germination: control of growth potential by cell-wall yielding in the embryo. Plant Cell and Environment 16:223-229.

Schroder, R. and R. Prasse. 2013. Cultivation and Hybridization Alter the Germination Behavior of Native Plants Used in Revegetation and Restoration. Restoration Ecology 21:793-800.

Seibert, A. C. and R. B. Pearce. 1993. Growth analysis of weed and crop species with reference to seed weight. Weed Science 41:52-56.

Seiler, G. J. 1992. Utilization of wild sunflower species for the improvement of cultivated sunflower. Field Crops Research 30:195-230.

Shafran-Nathan, R., T. Svoray, and A. Perevolotsky. 2013. The resilience of annual vegetation primary production subjected to different climate change scenarios. Climatic Change 118:227-243.

Sharif-Zadeh, F. and A. J. Murdoch. 2000. The effects of different maturation conditions on seed dormancy and germination of Cenchrus ciliaris. Seed Science Research 10:447-457. 
Small, E. 1984. Hybridization in the domesticated-weed-wild complex, Toronto.

Sneck, M. 2012. Evolutionary responses to global change: an experimental test of the effect of altered precipitation on hybridization rates in sunflower (Helianthus). Rice University.

Snow, A. A. and L. G. Campbell. 2005. Can feral radishes become weeds. Pp. 193-208. Crop ferality and volunteerism.

Snow, A. A., D. Pilson, L. H. Rieseberg, M. J. Paulsen, N. Pleskac, M. R. Reagon, D. E. Wolf, and S. M. Selbo. 2003. A Bt transgene reduces herbivory and enhances fecundity in wild sunflowers. Ecological Applications 13:279-286.

Snow, A. A., K. L. Uthus, and T. M. Culley. 2001. Fitness of hybrids between weedy and cultivated radish: Implications for weed evolution. Ecological Applications 11:934-943.

Solomon, S., G.-K. Plattner, R. Knutti, and P. Friedlingstein. 2009. Irreversible climate change due to carbon dioxide emissions. Proceedings of the National Academy of Sciences of the United States of America 106:1704-1709.

St Clair, C. R. and C. A. Fuller. 2014. Atrazine exposure increases time until cannibalistic response in the widow skimmer dragonfly (Libellula luctuosa). Canadian Journal of Zoology-Revue Canadienne De Zoologie 92:113-117.

Stachowicz, J. J., J. R. Terwin, R. B. Whitlatch, and R. W. Osman. 2002. Linking climate change and biological invasions: Ocean warming facilitates nonindigenous species invasions. Proceedings of the National Academy of Sciences of the United States of America 99:15497-15500.

Stanton, M. L., A. A. Snow, S. N. Handel, and J. Bereczky. 1989. The impact of a flowercolor polymorphism on mating patterns in experimental populations of wild radish (Raphanus raphanistrum L.). Evolution 43:335-346.

Stewart, C. N., M. D. Halfhill, and S. I. Warwick. 2003. Transgene introgression from genetically modified crops to their wild relatives. Nature Reviews Genetics 4:806-817.

Stokes, P. 1965. Temperature and seed dormancy. Springer, Berlin Heidelberg.

Templeton, A. R. 1979. A frequency dependent model of brood selection. American Naturalist 114:515-524.

Teo-Sherrell, C. P. A. 1996. The fates of weed seeds. Department of Agronomy University of Nebraska.

Thompson, K. and J. P. Grime. 1979. Seasonal variation in the seed banks of herbaceous species in ten contrasting habitats. Journal of Ecology 67:893921.

Tilman, D., K. G. Cassman, P. A. Matson, R. Naylor, and S. Polasky. 2002. Agricultural sustainability and intensive production practices. Nature 418:671-677.

Tuberosa, R. and S. Salvi. 2006. Genomics-based approaches to improve drought tolerance of crops. Trends in Plant Science 11:405-412.

Uwimana, B., M. J. M. Smulders, D. A. P. Hooftman, Y. Hartman, P. H. van Tienderen, J. Jansen, L. K. McHale, R. W. Michelmore, C. C. M. van de Wiel, and R. G. F. Visser. 2012. Hybridization between crops and wild relatives: the contribution of cultivated lettuce to the vigour of crop-wild hybrids under drought, salinity and nutrient deficiency conditions. Theoretical and Applied Genetics 125:1097-1111. 
Vegis, A. 1964. Dormancy in higher plants. Annual Review of Plant Physiology 15:185-\&.

Venable, D. L. 1989. Modeling the evolutionary ecology of seed banks. Academic Press, San Diego, CA.

Verdu, M. and A. Traveset. 2005. Early emergence enhances plant fitness: A phylogenetically controlled meta-analysis. Ecology 86:1385-1394.

Visser, M. E. 2008. Keeping up with a warming world; assessing the rate of adaptation to climate change. Proceedings of the Royal Society B-Biological Sciences 275:649-659.

Vogel, K. P. and K. B. Mitchell. 2008. Heterosis in switchgrass: Biomass yield in swards. Crop Science 48:2159-2164.

Walther, G. R., E. Post, P. Convey, A. Menzel, C. Parmesan, T. J. C. Beebee, J. M. Fromentin, O. Hoegh-Guldberg, and F. Bairlein. 2002. Ecological responses to recent climate change. Nature 416:389-395.

Warwick, S. I. and A. Francis. 2005. The biology of Canadian weeds. 132. Raphanus raphanistrum L. Canadian Journal of Plant Science 85:709-733.

Welch, M. E. and L. H. Rieseberg. 2002. Habitat divergence between a homoploid hybrid sunflower species, Helianthus paradoxus (Asteraceae), and its progenitors. American Journal of Botany 89:472-478.

Whitney, K. D., J. R. Ahern, and L. G. Campbell. 2009. Hybridization-prone plant families do not generate more invasive species. Biological Invasions 11:12051215.

Wright, K. J., G. P. Seavers, N. C. B. Peters, and M. A. Marshall. 1999. Influence of soil moisture on the competitive ability and seed dormancy of Sinapis arvensis in spring wheat. Weed Research 39:309-317.

Xu, X., R. A. Sherry, S. Niu, D. Li, and Y. Luo. 2013. Net primary productivity and rainuse efficiency as affected by warming, altered precipitation, and clipping in a mixed-grass prairie. Global Change Biology 19:2753-2764.

Yahdjian, L. and O. E. Sala. 2002. A rainout shelter design for intercepting different amounts of rainfall. Oecologia 133:95-101.

Yang, X., H. Xia, W. Wang, F. Wang, J. Su, A. A. Snow, and B.-R. Lu. 2011. Transgenes for insect resistance reduce herbivory and enhance fecundity in advanced generations of crop-weed hybrids of rice. Evolutionary Applications 4:672684.

Young, K. R. 2001. Germination and emergence of wild radish (Raphanus raphanistrum L.) The University of Melbourne.

Zammit, C. A. and P. H. Zedler. 1988. The influence of dominant shrubs, fire, and time since fire on soil seed banks in mixed chaparral. Vegetatio 75:175-187.

Zhu, Y., X. Yang, C. C. Baskin, J. M. Baskin, M. Dong, and Z. Huang. 2014. Effects of amount and frequency of precipitation and sand burial on seed germination, seedling emergence and survival of the dune grass Leymus secalinus in semiarid China. Plant and Soil 374:399-409. 